\title{
Interacting effects of land use type, soil microbes and plant traits on aggregate stability
}

Article

Accepted Version

Creative Commons: Attribution-Noncommercial-No Derivative Works 4.0

Merino-Martín, L., Stokes, A., Gweon, H. S. ORCID:

https://orcid.org/0000-0002-6218-6301, Moragues-Saitua, L., Staunton, S., Plassard, C., Oliver, A., Le Bissonnais, Y. and Griffiths, R. I. (2021) Interacting effects of land use type, soil microbes and plant traits on aggregate stability. Soil Biology \& Biochemistry, 154. 108072. ISSN 0038-0717 doi:

https://doi.org/10.1016/j.soilbio.2020.108072 Available at https://centaur.reading.ac.uk/94779/

It is advisable to refer to the publisher's version if you intend to cite from the work. See Guidance on citing.

To link to this article DOI: http://dx.doi.org/10.1016/j.soilbio.2020.108072

Publisher: Elsevier

All outputs in CentAUR are protected by Intellectual Property Rights law, including copyright law. Copyright and IPR is retained by the creators or other copyright holders. Terms and conditions for use of this material are defined in the End User Agreement. 


\section{CentAUR}

Central Archive at the University of Reading

Reading's research outputs online 
1 Interacting effects of land use type, soil microbes and plant traits on aggregate stability

3 Author list / address list:

4 Luis Merino-Martín ${ }^{1,2,3}$, Alexia Stokes ${ }^{1}$, Hyun S. Gweon ${ }^{2}$, Lur Moragues-Saitua ${ }^{4}$, Siobhan Staunton ${ }^{5}$,

5 Claude Plassard ${ }^{5}$, Anna Oliver ${ }^{2}$, Yves Le Bissonnais ${ }^{6}$, Robert I. Griffiths ${ }^{2}$.

$6 \quad{ }^{1}$ Amap, University Montpellier, INRAE, Cirad, Cnrs, Ird, Montpellier, France.

$7 \quad{ }^{2}$ Centre for Ecology \& Hydrology, Crowmarsh Gifford, Wallingford, Oxfordshire, United Kingdom.

$8{ }^{3}$ CEFE, Univ Montpellier, CNRS, Univ Paul Valéry Montpellier 3, EPHE, IRD, Montpellier, France.

$9 \quad{ }^{4}$ Department of Conservation of Natural Resources, NEIKER-Tecnalia, Derio, Spain.

$10 \quad{ }^{5}$ Eco\&Sols, INRAE, CIRAD, IRD, Institut Agro, Univ Montpellier, Montpellier, France.

$11{ }^{6}$ LISAH, INRAE, IRD, Institut Agro, University Montpellier, Montpellier, France.

12 "Corresponding author. Tel.: +33(0)789288168. E-mail address: luismerinomartin@gmail.com (L.

13 Merino-Martín).

For submission to Soil Biology and Biochemistry.

Article type: Full paper.

Word count:

\begin{tabular}{|l|l|l|l|}
\hline Total word count (excluding & 10329 & No. of figures: & 8 \\
summary, highlights, references & & & \\
\hline and legends): & 427 & No. of Tables: & 6 \\
\hline Summary: & 1396 & No of Supporting & 6 tables \\
& Information files: & 5 figures \\
& & & 1 research note \\
\hline Materials and methods: & 4497 & & \\
\hline Results: & 2013 & & \\
\hline Discussion: & 1989 & & \\
\hline Conclusions: & 325 & & \\
\hline Acknowledgements: & 96 & & \\
\hline
\end{tabular}


Soil aggregates are critical to soil functionality, but there remain many uncertainties with respect to the role of biotic factors in forming aggregates. Understanding the interacting effects of soil, land use type, vegetation and microbial communities is a major challenge that needs assessment in both field and controlled laboratory conditions, as well as in bulk and rhizosphere soils. To address these effects and their feedbacks, we first examined the influence of soil, root and litter characteristics along a land use gradient (ancient woodland, secondary woodland, grassland, pasture and arable land) on microbial community structure (in both bulk and rhizosphere soil), as well as on aggregate stability. Then, we performed an inoculation experiment where we extracted soil columns from the arable and secondary woodland and used a third unstructured loamy soil as a control. We sterilized these three soils to remove microbial communities, and then either inoculated the tops of sterilized soil columns with soil from the secondary woodland or the arable field sites. Control columns of all soil types were not inoculated. In a fully-crossed design, we planted two species possessing distinct root system morphological traits: Brachypodium sylvaticum (fibrous system with many thin and fine roots) and Urtica dioica (taproot system with few fine roots). After four months, microbial communities (in bulk and rhizospheric soil) and aggregate stability were measured, along with root traits. In both the field and laboratory experiments, bacterial (16S) and fungal (ITS) biodiversity was determined using high throughput sequencing. In the field study we found that: i) there were strong relationships between aggregate stability and microbial community composition that were driven by land use, ii) the relationship between aggregate stability along the land use gradient and the trophic nature of bacterial communities was not significant, but that certain soil, root and litter parameters shaped bacterial phyla, with oligotrophic bacteria conditioned by the rhizosphere niche, and copiotrophic phyla more dependent on bulk soil conditions, iii) land use gradient (from woodland to arable), reduced the relative abundance of saprotrophic and ectomycorrhizal fungi with an increase in the relative abundance of Ascomycota and a reduction in the relative abundance of Basidiomycota. In the laboratory experiment we found that: i) the inoculation of sterilized soils with soils from the field significantly increased aggregate stability in control soil that was initially poorly structured, ii) the 
48 soils were used as inoculums and iii) these effects were affected significantly by root length density.

49 Our results show that microbial communities influence soil structure and that bacterial communities

50 are intimately associated to rhizospheric conditions and root traits (of which root length density was

51 the most pertinent).

52 Key words: bacteria, fungi, glomalin, ergosterol, ITS, root traits, root systems, soil structure, 16S. 


\section{Introduction}

54

55

Soil structure is an essential factor driving the success of many ecosystem services worldwide (Adhikari and Hartemink, 2016), but most soils have been severely degraded in recent decades, due largely to anthropogenic pressures (Jie et al., 2002; Peng et al., 2015). Therefore, the capacity of soil to retain water, maintain biodiversity, sustain agriculture and resist flooding, erosion and landslides is compromised, unless we can find mechanisms by which soil structure can be restored rapidly. Soil is composed of a solid phase of particles and a pore phase that provides pathways for the transport of water, nutrients and gases, as well as habitats for microorganisms and fauna. The spatial configuration of soil particles and pores is arranged in aggregates and their stability is an important aspect of soil structure. Apart from soil texture (Bissonnais and Arrouays, 1997), diverse biotic and abiotic factors drive the rate of aggregation and its stability, e.g. microorganisms (Tisdall, 1994; Chenu and Sotzky, 2002; Lehmann et al., 2017), fauna (Lee and Foster, 1991; Ayuke et al., 2011), litter and root traits (Baumert et al., 2018; Poirier et al., 2018), environmental variables (e.g., tillage, freeze-thaw, wetting and drying cycles) (Lavee et al., 1996; Six et al., 1998; Gispert et al., 2013b) and inorganic binding agents (e.g., clay minerals, oxides and polyvalent cations such as calcium) (Denef and Six, 2005). Although many studies have focused on how individual factors modify soil aggregation and stability, very few have considered combinations of driving factors and their effects (Six et al., 2004; Baumert et al., 2018), particularly complex biotic factors. However, a better understanding of these interactions will improve soil restoration and the production of ecosystem services (Lavelle et al., 2020).

The importance of biotic factors for soil aggregation, and in particular soil microorganisms, was first suggested by Tisdall (1994) and has since been recognized worldwide (e.g. Degens, 1997; Chotte, 2005; Gupta and Germida, 2015). In a global meta-analysis, Lehmann et al. (2017) found a positive effect of soil biota on aggregation, with bacteria and fungi being generally more important for aggregation than other groups. Good soil structure is usually associated with high microbial biomass (Degens, 1997) and activity (Cui and Holden, 2015), mainly through the chemical binding action of microbial compounds such as bacterial extracellular polymeric substances (EPS) or soil proteins, or through the physical enmeshment of soil particles by fungal hyphae (Oades and Waters, 1991; Rillig 
and Mummey, 2006). Rillig et al. (2002a,b) attributed the positive effect of plant roots on aggregation to the excretion of a protein by arbuscular mycorrhizal fungi (AMF) called glomalin. This protein is operationally defined by its extraction method and belongs to a group of proteins after called glomalin-related soil proteins (GRSPs) that are no longer believed to be solely of fungal origin.

Ergosterol is the most abundant sterol in fungal cell membranes and since fungal hyphae enmeshment is a major factor for the formation of macroaggregates, it should be related to aggregate stability. Yet, the feedback mechanisms between aggregate formation and stability and the influence of microbial communities are not fully understood and identifying the relationships between changes in microbial community structure and GRSP and ergosterol are key for understanding soil aggregation processes.

Root system morphology can influence soil aggregation through changes in the distribution of carbon inputs into soil (Carter et al., 1994; Degens, 1997). Fine roots have direct effects on macroaggregate stability through the production of mucilage and exudates and indirect effects through the promotion of hyphal growth and the release of root-derived particulate organic matter (POM) that stimulate microbial activity (Morel et al., 1991; Miller and Jastrow, 1992; Brax et al., 2020). Consequently, plants with fibrous root systems, that have numerous, evenly distributed thin and fine roots, may have more available mucilage/exudates, as well as more easily degradable POM, than plants with taproot systems. Taproot systems generally comprise one large central root and less thin or fine roots (Miller and Jastrow, 1992; Degens, 1997), thus the potential input of total carbon into soil is reduced. We ask therefore, if root system morphology, and individual root traits such as diameter, length and carbon and nitrogen content (Saleem et al., 2018), influence the composition of microbial communities and so can modify macroaggregate formation and stability.

Soil aggregates are important for microbial community ecology, evolution and for microbially mediated cycles (Goebel et al., 2009; Rillig et al., 2016; Rillig et al., 2017). The heterogeneity of pores and water films on soil particles leads to a diversity of microhabitats and gradients of abiotic traits (e.g. nutrients and $\mathrm{pH}$ ) at microscales (Or et al., 2007). Soil carbon type and availability provides strong selective pressures for the different lifestyle strategies among copiotrophs (common in carbon-rich environments) and oligotrophs (present in habitats of low carbon flux) (Fierer et al., 
2007; Eilers et al., 2010; Trivedi et al., 2017). Trivedi et al. (2017) showed that aggregate size modulated the effects of management practices on soil carbon, with oligotrophs (e.g. Acidobacteria, Chloroflexi and Verrucomicrobia) inhabiting microaggregates containing higher proportions of recalcitrant carbon and copiotrophs (e.g. $\alpha$ and $\beta$ Proteobacteria, Bacteroidetes and Actinobacteria) living in macroaggregates with more labile carbon. Hence, soils with high macroaggregate stability should be dominated by copiotrophs. However, aggregate size is not the only factor influencing the abundance of copiotrophs and oligotrophs. Lauber et al. (2009) and Carbonetto et al. (2014) showed that agro-systems had a higher abundance of copiotrophs than in forests, probably because of greater nitrogen fertilization stimulating copiotrophic communities (Fierer et al., 2012). Complex interactions in soil can influence the abundance of different lifestyle strategies, e.g., rhizosphere communities are enriched with rhizodeposits (Dennis et al., 2010) and as a consequence, increase copiotroph abundance compared to bulk soil (Peiffer et al., 2013; Lladó and Baldrian, 2017). However, studies on how root and litter traits affect the abundance of these trophic modes in the different soil niches are notably lacking (Saleem et al., 2018), even though these scaled down studies are still needed to decipher the rules of rhizosphere community assembly (Brunel et al., 2020). The disturbance of soils through management also decreases soil fungal diversity, increasing the prevalence of generalist taxa, reducing the relative abundances of saprotrophic and ectomycorrhizal fungi and increasing the abundance of pathogenic fungi (Mueller et al., 2016; Marín et al., 2017). Managed land use types also possess more Ascomycota and less Basidiomycota compared to undisturbed natural ecosystems (de Castro et al., 2008; Mueller et al., 2016). Here, we ask if differences in the abovementioned bacterial and fungal trophic modes are due mainly to differences in aggregate formation, soil chemical characteristics or plant traits, along a land use gradient.

Since the complex feedbacks between aggregate formation and microbial communities are not fully understood, studies that integrate field observation with experimental testing are needed. Here, we performed two studies to determine the combined effects of soil type, root system morphological traits and microbial communities on soil aggregation and stability. We first surveyed these responses in the field across a gradient of different land use types (grassland, pasture, arable land, secondary woodland 
and ancient woodland) and hypothesized (hypothesis 1) that there are strong relationships between soil aggregate stability and microbial community structure that are driven by land use. Additionally, we hypothesize (hypothesis 2) that soils of higher aggregate stability will have characteristic communities comprising increased bacterial copiotrophs and increased relative abundance of saprotrophic and ectomycorrhizal fungi related to a decrease in the relative abundance of Ascomycota and an increase of Basidiomycota. However, this relationship may be influenced by other edaphic factors (e.g. soil nitrogen content) and root and litter traits, or soil habitat (e.g., with the rhizosphere niche favouring copiotrophic bacterial communities).

Then, to experimentally test interactive effects of plants and microbes on aggregate stability, we performed a controlled experiment where we sterilized soil samples from arable land and secondary woodland as well as a control soil; and inoculated into sterilized soil in which was grown two species of herbaceous plants with different root system morphologies. We hypothesize (hypothesis 3 ) that very fibrous root systems will increase aggregate stability, because more labile carbon will be available for microbial communities from fine root exudates and mucilage. We further hypothesize (hypothesis 4) that the effect of inoculation on aggregate stability will be greater with the inoculum coming from the soil with highest aggregate stability (secondary woodland), and this is related to source microbial community characteristics (measured using sequencing, GRSP, fungal biomass ergosterol ).

\section{Material and methods}

\subsection{Field sampling}

The study site is located in Wytham, Oxfordshire, southern England $\left(1^{\circ} 20^{\prime} \mathrm{W}, 51^{\circ} 47^{\prime} \mathrm{N}\right)$, where three land uses (grassland, pasture and arable) and two forests (ancient woodland and secondary woodland) were selected (Fig. 1). The forests are located in a 410 ha area of mixed woodlands and grassland, on a hill owned by the University of Oxford since 1943. These forests have been studied for several decades (Watts, 1969; Mihók et al., 2009) and the management history of the site is well documented (Gibson, 1986). In this area, we selected two forests for our study, an ancient woodland 
and a secondary woodland. The ancient woodland was traditionally managed by coppicing, but this management stopped between 40 and 100 years ago (differing locations were abandoned at different times). Acer pseudoplatanus L. and Quercus robur L. are abundant and Corylus avellana L. was the main coppice species. The dominant tree species of the naturally regenerated secondary woodland are Fraxinus excelsior L. and Acer pseudoplatanus L. (Savill et al., 2011). The ground flora of these woodlands is characterised by dominant Mercurialis perennis (dog's mercury) and changeable combinations of Endymion non-scripta (bluebell), Circaea lutetiana, Geum urbanum, Arum maculatum and Viola riviniana/reichenbachiana. Rubus fruticosa and bryophytes are common features of the field layer, in addition to the sedge Carex sylvatica and the grasses Poa trivialis and Brachypodium sylvatica (Butt et al., 2009). The three other land uses that were selected for this study are in an adjacent farmland. The arable site was cultivated with winter oats (Avena sativa L.) with no fertilization in 2014 (the sampling year) and with spring wheat (Triticum aestivum L.), fertilized at a rate $164 \mathrm{~kg} \mathrm{~N} \mathrm{ha}^{-1}$ and $7 \mathrm{t} \mathrm{ha}^{-1}$ of pig manure in 2013. In this arable site, soil was ploughed prior to our sampling. The other two sites, grassland and pasture, have been permanent pastures since 1992, with and Coral Rag developing soils with characteristic textures (Savill et al., 2011). All sites selected for this study are located on the Oxford Clay formation with Denchworth series soil (Eutric Vertic Stagnosols sensu USS Working Group WRB (2014)).

We collected soil samples to examine relationships in soil properties and microbial communities between sites and to provide background data for the inoculation experiment (see below). In each land use type, sampling was performed in three plots that were randomly located and samples were collected at a depth of 0-0.1 m except for aggregate stability samples and soil physicochemical properties that were collected at two depths $(0-10 \mathrm{~cm}$ and 20-30 cm). Depth can influence aggregate stability as it affects soil properties that are related to soil aggregate stability such as total organic carbon, total nitrogen, freeze-thaw cycles, etc. Four different soil samples were collected at each 
depth using sterilised material: (i) one soil cylinder $\left(1.01 \mathrm{dm}^{3}\right)$ for fine root analysis, (ii) 10 to $20 \mathrm{~g}$ of soil for microbial analysis placed in a plastic bag, (iii) soil for measurements of aggregate stability (at depths of $0-0.1 \mathrm{~m}$ and $0.2-0.3 \mathrm{~m}$ ) placed in $0.75 \mathrm{dm}^{3}$ containers and (iv) two soil samples for soil physicochemical analyses (at depths of 0-0.1 $\mathrm{m}$ and $0.2-0.3 \mathrm{~m}$ ). Litter from the surface of each soil core was sampled and kept in plastic bags for further analysis. A total of 15 samples of each type were collected: five land uses $\mathrm{x}$ three samples at each land use (except for aggregate stability and soil physicochemical properties where a total of 30 samples were collected, since six samples were collected at each plot; three at 0-0.1 $\mathrm{m}$ and three at 0.2-0.3 m). Soil samples were collected during July 7 th -10 th, 2014, at the peak of the summer season when microbial activity was expected to be at its maximum (Sarathchandra et al., 1988; Bardgett et al., 1997). Soil physicochemical properties of the five sites are given in Table 1.

Samples for root, litter and microbial analysis were stored at $-20^{\circ} \mathrm{C}$ prior to analysis. Soil samples for aggregate stability tests were air-dried at ambient temperature and analysed within one month.

\subsection{Laboratory inoculation experiment setup and sampling}

Intact soil cores with a diameter of $110 \mathrm{~mm}$ and a length of $150 \mathrm{~mm}\left(1.42 \mathrm{dm}^{3}\right)$ were collected from two field sites, arable land and secondary woodland in close proximity $(300 \mathrm{~m})$ for the laboratory inoculation experiment (Fig. 2). These two land uses were selected based on their large differences in soil aggregate stability and the minimal differences in soil textural properties (Table 1, Fig. 3). Thirtythree intact soil cores in the arable land site were collected on January $7^{\text {th }}, 2015$ and another set of 33 soil cores were collected in Wytham woods on January $8^{\text {th }}, 2015$ (Figs. S1 and S2a). Thirty-three pots were also filled with a commercial loamy soil (Boughton Kettering Loam, Boughton Loam Ltd, U.K.) to be used as a control treatment because this loamy soil lacks structural stability. Before and after sterilization, three samples from each provenance were collected for the measurement of physicochemical properties (Table S1).

After the field collection, the upper $30 \mathrm{~mm}$ of each soil core were removed to allow subsequent inoculation with $15 \mathrm{~mm}$ of non sterile soil from the arable and woodland soils $\left(0.14 \mathrm{dm}^{3}, 10 \%\right.$ of total 
volume) and $15 \mathrm{~mm}$ free for water ponding from irrigation (Figs. S2b and c). Thirty soil cores of each treatment (arable, woodland and control) were sterilized by gamma irradiation at Elgin Synergy Health PLC (Swindon, U.K.) with a dose between 50.5 and $52.1 \mathrm{kGy}$ on January $29^{\text {th }}$, 2015. Three cores of each soil were used to assess aggregate stability after gamma radiation and compared with the three non sterilized cores to verify that there was no effect of gamma irradiation on aggregate stability. Similarly, one soil sample in each of these three cores was collected to assess changes in microbial communities before and after the gamma radiation (three samples assessed before and three samples after).

After irradiation, the upper $15 \mathrm{~mm}$ of 18 soil cores was inoculated with fresh soil collected on February $9^{\text {th }}, 2015$ from the arable and woodland fields (nine soil cores from each provenance) and another set of nine soil cores were not inoculated (controls).

In three replicates of each combination, seeds from two species with either tap/adventitious (Urtica dioica) or fibrous (Brachypodium sylvaticum) root systems (sensu Fitter and Peat, 1994) were sown and a third treatment with no plants was used as a control (see Fig. 2 and Fig. S2 for a detailed illustration of procedure). Seeds of the two selected species, abundant in the Wytham area with contrasting root systems (Savill et al., 2011), were obtained from two different suppliers: Emorsgate Seeds, U.K. (B. sylvaticum) and Naturescape British Wildflowers, U.K. (U. dioica). Seeds were sterilized by placing them in a mesh bag and left for $30 \mathrm{~min}$ in a $2 \%$ sodium hypochlorite solution. They were removed from the bag and rinsed three times (for 5 min each) in sterilized deionised water (Commander et al., 2009). Then, seeds were germinated for three weeks in sterilized, deionised water before sowing. Ten seeds of each species were sown in each pot. Plants were grown in a temperature and light controlled facility for 4 months (February $12^{\text {th }}$ to June $15^{\text {th }}, 2018$, Fig. S2d). Pots were regularly weeded by hand for the first six weeks, but after that, the species that were sown commenced growth and weeding was ceased to avoid disturbance, although some seedlings emerged (particularly in treatments inoculated with arable soil). 
The first three irrigation events were performed with autoclaved deionised water, but afterwards, pots were watered with tap water using an automatic station (to promote downward movement of inoculum). To identify microbial communities existing in tap water and subtract them from the later microbial analysis on soils, 51 of tap water were collected at the beginning and the end of the experiment. This water was filtered, and DNA was extracted.

\subsection{Sample analysis}

\subsubsection{Soil respiration, moisture and physicochemical properties}

\subsubsection{Field study}

Soil collected in the field study was sieved at $2 \mathrm{~mm}$ after air drying and the physicochemical properties of the $<2 \mathrm{~mm}$ soil fraction was quantified by Natural Resource Management (Berkshire, UK). Soil $\mathrm{pH}$ was measured in water as 1:2.5 extract. Soil organic matter content (SOM) was determined via loss-on-ignition at $500{ }^{\circ} \mathrm{C}$ (Dean 1974). Total nitrogen $(\mathrm{N})$ and carbon $(\mathrm{C})$ were determined via the DUMAS method (Shea and Watts 1939). Available potassium (K) and magnesium $(\mathrm{Mg})$ were determined through ammonium nitrate extraction and available phosphorus $(\mathrm{P})$ was measured using the Olsen method (extraction with $0.5 \mathrm{M}$ sodium bicarbonate solution, (Olsen et al. 1954)). Soil texture was determined by laser-diffraction analysis (McCave et al. 1986). Each soil sample was previously digested in hydrogen peroxide solution to destroy the organic matter and sodium hexametaphospate to release the bound clay particles.

Aggregate stability was determined by the fast wetting standard method, ISO/CD 10930, developed by Le Bissonnais (Le Bissonnais, 1996). This methodology is appropriate to compare the behaviour of a large range of soils during rapid wetting (mimicking heavy rainstorms in summer). A quantity of $5 \mathrm{~g}$ of aggregates $(3-5 \mathrm{~mm})$ were gently immersed in $50 \mathrm{ml}$ of deionized water for 10 minutes; water was then removed with a pipette and the soil material was transferred to a $50 \mu \mathrm{m}$ sieve previously immersed in ethanol. The $50 \mu \mathrm{m}$ sieve immersed in ethanol was gently moved five times to separate fragments smaller and bigger than $50 \mu \mathrm{m}$. The $>50 \mu \mathrm{m}$ fraction was collected, oven-dried and gently 
dry-sieved by hand on a column of six sieves: $2000,1000,500,200,100$ and $50 \mu \mathrm{m}$. The mass percentage of each size fraction was calculated, and the aggregate stability was expressed by computation of the mean weight diameter (MWD).

\subsubsection{Laboratory inoculation experiment}

Soil samples collected from the inoculation experiment were sent to the chemical analysis laboratory of Forest Research (Surrey, UK). Soil $\mathrm{pH}$ was measured in a suspension of $5 \mathrm{~g}$ of soil with $25 \mathrm{ml}$ of water that was shaken on an orbital shaker for $15 \mathrm{~min}$ and settled for $45 \mathrm{~min}$ prior to $\mathrm{pH}$ measurement using a Sentek pH electrode (Reference method: ISO 10390). Total N, C, soil organic carbon (SOC) and inorganic carbon $\left(\mathrm{CaCO}_{3}\right)$ were measured with a combustion method using a Carlo Erba $\mathrm{CN}$ analyser (Reference method ISO 10694 \& 13878). Aggregate stability was measured with the fast wetting standard method described above.

We examined if microbial inoculation (through the addition of surface soil) changed soil texture and aggregate stability in deeper soil. The top $15 \mathrm{~mm}$ of soil was removed, and aggregate stability measured in the remaining soil. Texture of the aggregates obtained at the end of the experiment was measured by the CIRAD - US Analyses (Montpellier, France). The objective was to test whether the texture of the obtained aggregates was more related to the inoculated core (origin) or to the inoculum (inoculation treatment) and so, if there was any possible influence of inoculation with soil on the results of stability tests. Soil texture of aggregates was determined with an automated pipette method (Reference method AFNOR NF X 31-107) using a Texsol granulometer (ISITEC-LAB) on samples pre-treated following the standard method NF ISO 11464 (X31-412).

Two additional measurements in soils were made: i) the rate of exchange of $\mathrm{CO}_{2}$ (assimilation; $\mathrm{g}$ $\left.\left(\mathrm{CO}_{2}\right) \mathrm{m}^{-2} \mathrm{~h}^{-1}\right)$ measured with an EGM-4 Environmental Gas Monitor for $\mathrm{CO}_{2}$ and a SRC-1 Soil Respiration Chamber (PP Systems, Amesbury, MA, U.S.A.) in June 15th-17th, 2015 and ii) soil water content measured at two dates (June 8th and 12th, 2015) after irrigation with a WET Sensor (Delta-T Devices Ltd, Cambridge, UK). 
289

290

291

292

293

294

295

296

297

298

299

300

301

302

303

304

305

306

307

308

309

310

311

312

313

In the soil inoculation experiment, all aboveground vegetation biomass was cut at the surface at the end of the experiment and dried at $60^{\circ} \mathrm{C}$ until constant weight (Fig. S2e). Then, a core $\left(0.295 \mathrm{dm}^{3}\right)$ was collected in each of the pots for the assessment of root properties (Fig. S2f and Fig. S3).

Root samples from both the field study and the inoculation experiment were washed gently with deionised water and divided in two subsamples: 1) a representative subsample that was selected for scanning and later drying in the oven at $40^{\circ} \mathrm{C}(\mathrm{n}=3$ for each land use in the field experiment and $\mathrm{n}=$ 27 for each provenance; arable, woodland and control; in the inoculation experiment) and 2) remaining root material of the sample that was dried at $40^{\circ} \mathrm{C}$ until constant weight $(\mathrm{n}=3$ for each land use in the field experiment and $n=27$ for each provenance in the inoculation experiment). Both subsamples were weighed before and after drying. Roots selected for morphological measurement were stained with methylene blue $\left(1 \mathrm{gl}^{-1}\right)$ to increase the contrast and allow the detection of fine roots. Then, roots were placed in a tray with deionised water and scanned (Epson $\odot$ V700 Perfection) at a resolution of $1200 \mathrm{dpi}$. Analysed subsample roots were then recovered, and oven dried at $40{ }^{\circ} \mathrm{C}$ and weighed to obtain dry mass. Root images were analysed with the WinRhizo® software (Pro version 2007, Regent Instrument, Quebec, Canada) using the automatic thresholding option and Lagarde's mode, with a filter identifying roots when length was five times the width. We measured total root length and the length of roots in seven diameter classes (roots with a width of 0 - 1 mm were separated into $0.2 \mathrm{~mm}$ classes and roots with a width of $1-2 \mathrm{~mm}$ were separated into $0.5 \mathrm{~mm}$ classes). Debris was removed with a filter that eliminated fragments that were less than five times longer than their width. Specific root length (SRL) was calculated as the ratio between total root length and root dry mass. The percentages of very fine (VFR, diameter $<0.2 \mathrm{~mm}$ ) and fine (FR, $0.2<$ diameter $<1$ $\mathrm{mm}$ ) roots were defined as the ratio of length in the concerned root classes to total root length (Miller and Jastrow, 1990). Total root mass density (RMD) was calculated by the ratio of total root dry mass and the soil volume extracted. Total root length density (RLD) was calculated by the ratio of total root length and the soil volume extracted. Total root dry mass was calculated as the sum of the dry mass of 
roots selected for morphological analysis and those of the remaining roots. Root dry matter content (RDMC) was calculated as the ratio of the root dry weight and fresh weight.

The concentrations of water soluble compounds (cellulose, hemicellulose and lignin; $\mathrm{mg} \mathrm{g}^{-1}$ ) in root and litter samples from the field experiment $(\mathrm{n}=11$ for litter, i.e. 3 replicates $\mathrm{x} 4$ treatments $=12$ excluding 1 sample with insufficient mass; and $\mathrm{n}=4$ for roots as replicates were combined due to limited sample amount; "arable" was excluded from these measurements), were obtained by the Van Soest Method (Van Soest, 1963) with a Fibersac fibre analyser (Ankom, Macedon, USA). Root C and $\mathrm{N}$ concentrations were measured in roots from the field study ( $\mathrm{n}=12$, i.e. 3 replicates $\mathrm{x} 4$ treatments since arable was excluded from these measurements) and the inoculation experiment ( $\mathrm{n}=3$ for each treatment with roots) and litter $\mathrm{C}$ and $\mathrm{N}$ were measured in samples from the field experiment $(\mathrm{n}=15)$ using an elemental analyser (Thermo-Finnigan EA1112, Italy).

\subsubsection{Soil microbial communities}

\subsubsection{Obtaining rhizosphere and bulk soil samples}

In both the field study and laboratory inoculation experiment, roots were cleaned and rhizosphere and bulk soil samples obtained following the protocols of Bulgarelli et al. (2012, 2015). Briefly, loose soil was manually removed from the root system and stored as the bulk soil sample. Roots were collected in $50 \mathrm{ml}$ falcon tubes containing $10 \mathrm{ml}$ PBS-S buffer $\left(130 \mathrm{mM} \mathrm{NaCl}, 7 \mathrm{mM} \mathrm{Na}_{2} \mathrm{HPO}_{4}, 3 \mathrm{mM}\right.$ $\mathrm{NaH}_{2} \mathrm{PO}_{4}, \mathrm{pH} 7.0,0.02 \%$ Silwet L-77) and washed for 20 minutes at $180 \mathrm{rpm}$ on a shaking platform. These roots were transferred to a new falcon tube and subjected to a second washing treatment (20 minutes at $180 \mathrm{rpm}$ in $3 \mathrm{ml}$ PBS-S buffer). The soil suspensions collected in the falcon tubes after the first and second washing treatments were combined, centrifuged at $4000 \mathrm{~g}$ for $20 \mathrm{~min}$ and the pellet, considered as the rhizosphere sample, was frozen and stored at $-20^{\circ} \mathrm{C}$ until further analysis.

\subsubsection{DNA extraction, amplicon library construction and sequencing}

Total DNA was extracted from soil $(0.25 \mathrm{~g})$ and the rhizosphere fractions $(0.25 \mathrm{~g}$ when possible and the entire material available when quantity was less than $0.25 \mathrm{~g}$ ). DNA extraction was performed 
using PowerSoil@-htp96 Well Soil DNA Isolation Kit according to the manufacturer’s instructions (MOBIO Laboratories, UK).

Bacterial and fungal community biodiversity was assessed using Illumina amplicon sequencing of $16 \mathrm{~S}$ rRNA genes (bacteria) and the Internal transcribed spacer (ITS) region (fungi) to phylogenetically identify responsive taxa. A phylogenetic analysis was also performed for bacterial communities. Amplicon libraries were constructed according to the dual indexing strategy of Kozich et al. (2013), with each primer consisting of the appropriate Illumina adapter, an 8-nt index sequence, a 10-nt pad sequence, a 2-nt linker and the gene specific primer. For 16S, the V3-V4 hypervariable regions of the 16S rRNA gene was targeted using primers based upon the universal primer sequence 341F and 806R. For ITS, region 2 (ITS2) was amplified utilising the fITS7 (forward) and ITS4 (reverse) primer sequences described in Ihrmark et al. (2012). Additional methodological details of Illumina sequencing are described in Notes S1.

\subsubsection{Processing high-throughput data for community analysis}

Sequenced 16S rRNA paired-end reads were joined using PEAR (Zhang et al., 2014), quality filtered using FASTX tools (hannonlab.cshl.edu), length filtered with the minimum length of $300 \mathrm{bps,}$ presence of PhiX and adapters were checked and removed with BBTools (jgi.doe.gov/data-andtools/bbtools/), and chimeras were identified and removed with VSEARCH_UCHIME_REF (Rognes et al., 2016) using Greengenes Release 13_5 (at 97\%) (DeSantis et al., 2006). Singletons were removed and the resulting sequences were clustered into operational taxonomic units (OTUs) with VSEARCH_CLUSTER (Rognes et al., 2016) at 97\% sequence identity (Tindall et al., 2010). Representative sequences for each OTU were taxonomically assigned by RDP Classifier with the bootstrap threshold of 0.8 or greater (Wang et al., 2007) using the Greengenes Release 13_5 (full) (DeSantis et al., 2006) as the reference. Unless stated otherwise, default parameters were used for the steps listed. ITS2 sequences were processed using the PIPITS pipeline (Gweon et al., 2015), where OTUs were taxonomically assigned against the UNITE database (Release 31.01.2016, Koljalg et al. (2013). 
Hurisso et al. (2018) recently proposed the term autoclaved-citrate extractable protein (ACE), to avoid the implied assumption to the fungal origin of these proteins, but here we use the term GlomalinRelated Soil Proteins (GRSP) for ease of comparison with other studies. In the inoculation experiment, soil samples from the middle of each soil core were collected after the incubation period for the assessment of GRSP, thought to be a marker of arbuscular mycorrhizal activity. Soil samples were stored at $-20^{\circ} \mathrm{C}$ until further processing. Operationally-defined GRSP fractions were obtained using the extraction methods proposed by Wright and Upadhyaya (1996) as follows. Easily extractable soil protein $\left(\mathrm{GRSP}_{\mathrm{EE}}\right)$ was obtained by autoclaving soil in a solution of $20 \mathrm{mM}$ sodium citrate at $\mathrm{pH} 7$ for $30 \mathrm{~min}$. Total GRSP $\left(\mathrm{GRSP}_{\mathrm{T}}\right)$ was obtained by two successive autoclave extractions of soil in $50 \mathrm{mM}$ sodium citrate at $\mathrm{pH} 8$, each for $60 \mathrm{~min}$. In each case, the soil:solution ratio was 1:8 and phases were separated after cooling by centrifugation at $15000 \mathrm{~g}$ for $15 \mathrm{~min}$. For GRSP $\mathrm{T}_{\mathrm{T}}$, after the first autoclave cycle, solution was removed and replaced by the same volume of new addition of citrate solution, the mixture was vortexed to re-suspend the soil. The solutions were combined to form the total extract. Solutions were frozen until required for analysis. After thawing, samples were centrifuged again at $15000 \mathrm{~g}$ for 15 minutes to remove any precipitate that may have formed. Protein in both extracts were assayed using the Bradford technique with Bradford QuickStart kits from BioRad Laboratories (Hercules, CA, USA), calibrated against solutions of bovine serum albumin (BSA) within the working range of $0-200 \mathrm{mg} \mathrm{dm}^{-3}$. Following the recommendations proposed by Moragues-Saitua and co-workers (Moragues-Saitua et al., 2019), samples were diluted twofold (absorbance of about 0.1 at $465 \mathrm{~nm}$ ), to reduce the interference of co-extracted coloured compounds. A sample volume of $20 \mu \mathrm{l}$ were assayed in microplates with $230 \mu \mathrm{l}$ Bradford dye reagent. Optical density was measured at $595 \mathrm{~nm}$ in ThermoScientific Multiskan GO spectrometer (Waltham,MA, USA) and sample blank colour absorbance at $\mathrm{pH}=1$ corrected. 
Ergosterol, a proxy for active fungal biomass, was measured in soil samples that were obtained from the middle of each core of the inoculation experiment after the incubation period. Ergosterol was assessed following the method of Plassard et al. (2000). Briefly, ergosterol was extracted by mixing very gently $0.5 \mathrm{~g}$ of soil in $3 \mathrm{ml}$ of methanol containing polyclar $\left(0.5 \%\right.$, w/v) $\left(\mathrm{CAS} \mathrm{n}^{\circ} 9009-39-8\right)$ in screw-cap tubes. After firm closure, tubes were incubated at $4^{\circ} \mathrm{C}$ for $24 \mathrm{~h}$, without shaking as ergosterol is rapidly lost by oxidation. The concentration of ergosterol in filtered $(0.45 \mu \mathrm{m})$ methanol extracts was determined at $270 \mathrm{~nm}$ by high-performance liquid chromatography using a C18 column

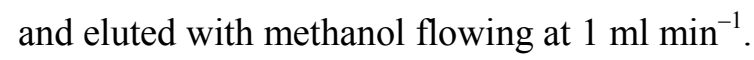

\subsection{Statistical analysis}

\subsubsection{Field study}

First, we examined the differences on soil, root and litter physicochemical characteristics and aggregate stability among the different land uses. Then, we performed NMDS data ordinations of microbial data and tested of the effect of land use and sample fraction on their structure (Permutational Multivariate Analysis of Variance, PERMANOVA). Finally, we studied the correlation between microbial community composition and environmental variables (Spearman correlations between Shannon diversity indexes and distance-based redundancy analysis, dbRDA).

Soil aggregate stability, soil physicochemical properties and root and litter traits were analysed by analysis of variance (ANOVA) and post hoc Tukey's honestly significant difference (HSD) test. The land use explanatory variable was treated as a factor. Relative abundance of the different phyla and trophic modes were analysed by ANOVA and post hoc HSD with land use and sample fraction as explanatory variables. All variables tested fulfilled ANOVA assumptions except for the Saprotroph trophic mode that was inverse transformed to fulfil ANOVA assumptions. The relationships between the relative abundance of bacterial phyla and the soil physicochemical variables, root and litter traits were tested using Spearman correlations. 
414 Similarities/dissimilarities between microbial communities were displayed using non-metric multi-

415 dimensional scaling (NMDS) of Bray-Curtis dissimilarity for bacterial and fungal species matrices.

416 To indicate similarities between treatments on the NMDS configuration, the points on the NMDS

417 ordination were overlapped with spider diagrams and convex hull polygons indicating land use and

418 soil fraction was indicated with different symbols. Surfaces were added to show soil aggregate

419 stability data on the ordinations. PERMANOVA tests (adonis R function) were performed for the

420 bacteria and fungi species matrices as the response and the two different factors (land use and soil

421 fraction) as the explanatory variables.

The Shannon diversity index for bacteria and fungi was calculated for each land use and sample fraction (rhizosphere and bulk soil samples). The relationships between the microbial community composition and the soil physicochemical variables, root and litter traits were tested using Spearman correlations between these variables and alpha (Shannon diversity index) and beta diversities (NMDS first and second axis) and a db-RDA. In order to select the environmental parameters to be included in the constrained ordination, an initial db-RDA including all parameters was performed followed by a stepwise model selection using Generalized Akaike Information Criterion (AIC, ordistep function with a backward direction). Finally, the db-RDA analysis was performed only for the variables obtained. ANOVA tests were performed on the final constrained ordination to confirm that the first two axes and the environmental variables and the final constrained ordination were significant.

\subsubsection{Laboratory inoculation experiment}

First, we explored the differences on soil, vegetation and root traits and aggregate stability among the different combinations of treatments: i) origin (control, arable and woodland), ii) inoculation (not inoculated, arable and woodland) and iii) root treatment (no roots, fibrous and tap). Soil physicochemical properties, aboveground vegetation biomass, root traits, aggregate stability and aggregate fractions were analysed by ANOVA when ANOVA assumptions were fulfilled and with Kruskal Wallis tests when they were not fulfilled. Origin, inoculation, and root treatment were used as explanatory variables and were treated as factors. PCA was performed with a selection of variables 
used for the description of soil, vegetation, and root properties. Variables included in the PCA were: aboveground biomass, $\mathrm{CO}_{2}$ assimilation, soil water content, soil $\mathrm{pH}, \mathrm{SOC}$, soil C:N, SRL, VFR, MRD, RMD, RLD, root C:N, GRSP ${ }_{\mathrm{T}}$, ergosterol and MWD. These variables were selected based on their correlation and ecological significance (i.e. variables that were correlated but their source was ecologically different were kept, e.g. soil C:N and root C:N). Apart from the ANOVA performed for MWD with soil origin, inoculation and root treatment as factors, an additional analysis of covariance (ANCOVA) model was tested and included RLD to explore separately the effect of root chemical (i.e. species effect) and root physical properties (quantity of roots) within the effect of root treatment.

Non-metric multi-dimensional scaling (NMDS) of Bray-Curtis dissimilarity were performed for bacterial and fungal species matrices obtained for bulk soil fraction (since the rhizosphere sample fraction was only available for treatments where roots were present). To indicate similarities between treatments on the NMDS configuration, the points on the NMDS ordination were overlapped with convex hull polygons indicating the inoculation treatment, origin was indicated with symbols of different colour and root treatment was indicated with different symbol shape. PERMANOVA tests (adonis R function) were performed for the bacteria and fungi species matrices as the response and the three different treatments (origin, inoculation and root treatment) as the explanatory variables using species matrix of bulk soil and rhizosphere fractions. Additional Analysis of similarities (ANOSIM) were performed to test the effects of root treatment, and inoculation in each of the combinations of the experimental design in bulk soil sample fractions.

The Shannon diversity index for bacteria and fungi was calculated for each pot. In line with the field study, Spearman correlations between soil, vegetation, root traits and aggregate stability variables and alpha (Shannon diversity index) and beta diversities (NMDS first and second axis) were calculated. Likewise, a db-RDA was performed on species matrices of bacterial and fungal communities obtained from the bulk soil fraction. Environmental parameters included in the db-RDA were selected by a stepwise model selection process using AIC similar to the process performed for the field study. ANOVA tests were performed on the final constrained ordination to confirm that the first two axes and the environmental variables and the final constrained ordination were significant. 
467 Finally, we explored the textural class (proportion of clay, fine silt, coarse silt, fine sand, coarse sand)

468 of soil aggregates used for the stability tests, to examine whether there was any possible influence of

469 inoculation on the results of stability tests. We depicted a soil texture triangle to show the texture of

470 the different treatment combinations and overlapped with ellipses discriminating the origin of the

471 sample and symbols of different colours indicating inoculation treatment. Then, we performed a

472 weighted Classical (Metric) Multidimensional Scaling with textural properties to explore the

473 differences among origin and inoculation treatment, the points on this ordination were overlapped

474 with convex hull polygons indicating the origin, and inoculation was indicated with symbols of

475 different colour. Finally, we performed an analysis of similarities (ANOSIM) to test the effects of

476 origin and inoculation treatments on the textural properties of aggregates.

477 All analyses were performed in RStudio Version 3.6.0 (R Core Team, 2019) using the vegan

478 (Oksanen et al., 2019) and ade4 (Dray and Dufour, 2007) packages. 

among land use types

\subsubsection{Relationships between land use and soil, litter and root properties}

Soil physicochemical properties from samples taken at depths of $0-0.1 \mathrm{~m}$ and $0.2-0.3 \mathrm{~m}$, differed between land uses (Table 1). The arable field site had a higher $\mathrm{pH}$ and nutrient contents $(\mathrm{P}, \mathrm{K})$ but lower $\mathrm{Mg}, \mathrm{SOC}, \mathrm{N}$ and $\mathrm{C}$ than the other sites. The pasture site had the highest $\mathrm{SOC}, \mathrm{N}$ and $\mathrm{C}$ contents. All soils had a loamy texture, but ancient and secondary woodlands and arable field sites possessed a clay loam texture and both the grassland and pasture had a sandy loam texture. Roots had similar traits between ancient and secondary woodlands (Table S2), with lower SRL $(19.68 \pm 4.06$ and $13.16 \pm 1.16 \mathrm{~m} \mathrm{~g}^{-1}$ respectively), lower MRD $(0.44 \pm 0.01$ and $0.56 \pm 0.02 \mathrm{~mm}$ respectively), lower RLD (5.69 \pm 1.26 and $\left.5.12 \pm 0.90 \mathrm{~km} \mathrm{~m}^{-3}\right)$, higher $\mathrm{N}$ content $\left(1.18 \pm 0.06\right.$ and $1.48 \pm 0.01 \mathrm{mg} \mathrm{g}^{-1}$ respectively) and lower C:N (35.04 \pm 2.57 and $27.72 \pm 0.69$ respectively) than the other land use types. Litter traits had similar trends to that observed in roots: litter from ancient and secondary woodlands had higher hemicellulose (17.02 \pm 1.01 and $19.88 \pm 0.20 \mathrm{mg} \mathrm{g}^{-1}$ respectively) and $\mathrm{N}$ content $(1.37 \pm 0.07$ and $1.43 \pm 0.02 \mathrm{mg} \mathrm{g}^{-1}$ respectively) and lower C:N (26.62 \pm 1.35 and $26.21 \pm 1.08$ respectively), compared to the other land use types. Soil aggregate stability was significantly different among land uses (Fig. 3), with pasture having the greatest MWD and arable land the lowest, with the other three land uses possessing an intermediate behaviour. A clear effect of soil depth was also identified (Fig. 3), highlighting the role of processes at the surface that promote aggregate stability and justifying the subsequent focus on soil sampled at a depth of $0-0.1 \mathrm{~m}$.

\subsubsection{Effects of land use on the structure of bacterial and fungal communities}

Land use type affected the relative abundance of Actinobacteria, Proteobacteria and Verrucomicrobia (Fig. 4a) with the arable land having a significantly higher relative abundance of Actinobacteria and lower relative abundance of Proteobacteria and Verrucomicrobia compared to other land uses. In addition, a significant interaction was found between land use and sample fraction for Acidobacteria, with a decreased relative abundance in woodland rhizosphere soils but not in woodland bulk soil 
samples. Sample fraction also significantly affected the relative abundance of Bacteriodetes and Verrucomicrobia (Fig. 4a), which were more abundant in bulk soils for Bacteroidetes and the opposite for Verrucomicrobia, with only a significant effect of land use type in the rhizosphere for Verrucomicrobia. Correlations between relative abundance of bacterial phyla and soil, root and litter variables showed that oligotrophic Chloroflexi and Verrucomicrobia were significantly correlated to root and litter physicochemical variables (i.e. SRL, VFR, MRD, RDMC, root and litter N and C:N, litter lignin) in the rhizosphere but not in the bulk soil (Table 2). Conversely, copiotrophic phyla (Actinobacteria, Bacteroidetes and Proteobacteria) showed similar correlations in bulk soil but not in the rhizosphere. The relative abundance of these copiotrophic phyla were correlated with some soil physicochemical traits ( $\mathrm{pH}, \mathrm{P}$, sand content) and for the specific case of Actinobacteria, this phylum showed significant correlations with root and litter traits (SRL, RMD, root N, C:N and hemicellulose and litter fibres, Table 2). For fungi, land use influenced the relative abundance of Ascomycota and Zygomycota, with a significant effect of sample fraction for Ascomycota (Fig. 4b). Arable land had the highest relative abundances of Ascomycota, whilst the secondary woodland possessed the lowest relative abundance of Ascomycota and the highest abundance of Zygomycota. Regarding trophic mode, land use type affected the relative abundance of saprotrophs and symbiotrophs with the arable field having the lowest abundances. The land use type also influenced the relative abundance of fungi belonging to an unspecific category that includes pathotrophs, saprotrophs and symbiotrophs, with the highest relative abundance in secondary woodland (Fig. 4c).

NMDS ordinations showed that bacterial and fungal communities were markedly distinct between land use types (Figure 5a). These findings were supported by the PERMANOVA performed for the bacterial and fungal species matrices (Table 3), which showed that land use type was by far the most important factor structuring bacterial and fungal communities $\left(\mathrm{R}^{2}=0.44 \mathrm{p}=0.01\right.$ and $\mathrm{R}^{2}=0.53 \mathrm{p}=0.01$, respectively) irrespective of whether communities were taken from the rhizosphere or bulk soils (Table 3). Significant trends between changes in community structure and soil aggregate stability were also observed, with arable communities having the lowest MWD (Figure 5a). 

among land use types

The results of the relationships between soil physicochemical properties, root and litter traits (Tables 1 and S2, Figure 3) and microbial community composition are shown in the db-RDA (Figure 5b) and Spearman correlations with alpha and beta diversities (Table S4). The final db-RDA analysis (Figure 5b) shows only the environmental parameters that were selected through stepwise model selection: MWD, soil $\mathrm{pH}$ and $\mathrm{P}$, and MRD for bacterial communities and MWD, RLD, FR and soil $\mathrm{pH}$ and $\mathrm{P}$ for fungal communities. There was a clear separation between land uses for bacterial communities (Figure 5b), with three main groups: i) woodlands (ancient and secondary), ii) grasslands (actively and not actively grazed) and iii) arable land. Soil from woodlands had significantly greater MWD and higher MRD, whereas arable land had a significantly greater soil $\mathrm{pH}$ and $\mathrm{P}$ (Figure $5 \mathrm{~b}$ ). For fungal communities, a similar configuration was found among the three land use types, but soil from grasslands had a significantly higher RLD, and woodlands had a greater FR. ANCOVA tests performed on the final constrained ordination confirmed that the first two axes, the environmental variables and the final constrained ordination were significant.

Bacterial and fungal alpha diversities (Table S3) were not significantly correlated with any of the variables measured (Table S4). Bacterial beta diversity was significantly and positively correlated with soil $\mathrm{pH}$, clay and magnesium contents, soil C:N, FR, MRD, root and litter $\mathrm{N}$ and litter lignin and negatively correlated to MWD, sand content, SRL, VFR and root and litter C:N and hemicellulose. Similarly, fungal beta diversity was significantly and positively correlated $\left(\mathrm{p}<0.001\right.$ and $\left.\mathrm{R}^{2} \geq 0.65\right)$ with soil $\mathrm{pH}$, clay and magnesium contents, soil C:N, FR, MRD, root $\mathrm{N}$, and litter lignin, and negatively with sand content, SRL, VFR, RLD, root C:N and root and litter hemicellulose (Table S4).

\footnotetext{
3.2. Laboratory inoculation experiment: Effect of microbial inoculation on soil aggregate stability and interactions with soil origin and root systems.
}

\subsubsection{Effects of soil origin, inoculation and root systems on soil properties and plant traits}


The PCA performed with a selection of variables used for the description of soil, plant and root traits explained $56.7 \%$ of the variance (Fig. 6). The first PCA axis (horizontal), accounted for $43.7 \%$ of the variation and the second PCA axis accounted for $13 \%$ of the variation. This PCA showed a clear differentiation between control, and either arable land or woodland. The main contributors to these differences were soil $\mathrm{pH}$, SOC and MWD. Control soil had significantly higher $\mathrm{pH}$, soil and root $\mathrm{C}: \mathrm{N}$ ratios and lower SOC, MWD, GRSP $\mathrm{T}_{\mathrm{T}}$ and ergosterol content compared to soils from the arable land and woodland.

All soil properties assessed (e.g. $\mathrm{pH}, \mathrm{SOC}, \mathrm{C}, \mathrm{N}$ ) were influenced significantly by the origin of the soil (i.e. control, arable and woodland, Table S5, p<0.05). Additionally, a significant effect of inoculation was found for soil water content $(\mathrm{p}<0.001)$, which may be because this was the only variable that was measured in the top $0.1 \mathrm{~m}$ of the soil profile, therefore including the soil used for inoculation. Aboveground plant biomass was significantly affected by soil origin and root system type $(p<0.001)$ but not by inoculation. Concerning root traits, soil origin affected significantly root biomass $(p=0.014), S R L, V F R, F R, M R D, N$ and $C: N(p<0.001)$ and root system type affected root biomass $(p<0.001)$, SRL $(p<0.020)$, RMD and RLD $(p<0.001)$ but no effect of inoculation was found (Table S5, Fig. 7).

\subsubsection{Effects of soil origin, inoculation and root systems on the structure of bacterial and fungal} communities.

NMDS ordinations showed that bacterial and fungal communities were markedly distinct between inoculation treatments and soil origin but there were weaker effects of root system types (Figure 8a). These findings were supported by the PERMANOVA performed for the bacterial and fungal species matrices (Table 4), which showed that the main factors structuring bacterial communities were inoculation $\left(\mathrm{R}^{2}=0.18, \mathrm{p}<0.001\right)$ and origin $\left(\mathrm{R}^{2}=0.05, \mathrm{p}<0.001\right)$ in bulk soil, and inoculation $\left(\mathrm{R}^{2}=0.26\right.$, $\mathrm{p}<0.001)$, origin $\left(\mathrm{R}^{2}=0.09, \mathrm{p}<0.001\right)$ and root system $\left(\mathrm{R}^{2}=0.06, \mathrm{p}<0.001\right)$ in the rhizosphere. The results observed for fungal communities were different, with inoculation $\left(\mathrm{R}^{2}=0.16, \mathrm{p}<0.001\right)$, origin $\left(\mathrm{R}^{2}=0.03, \mathrm{p}<0.001\right)$ and root system $\left(\mathrm{R}^{2}=0.02, \mathrm{p}<0.001\right)$ significantly affecting fungal communities in 
the bulk soil. However, for fungal communities in the rhizosphere, only inoculation treatments $\left(\mathrm{R}^{2}=0.24, \mathrm{p}<0.001\right)$ and soil origin $\left(\mathrm{R}^{2}=0.08, \mathrm{p}<0.001\right)$ had significant effects. Overall, considering the $\mathrm{R}^{2}$ values, the influence of root system type was stronger on the structure of bacterial communities than for fungal communities. Furthermore, the interaction between origin and inoculation was significant in all cases $(p<0.001)$, indicating that the effect of inoculation was affected by the soil origin. Additionally, for fungal communities in the bulk soil, the effect of root system type was affected by both inoculation (inoculation* root treatment $R^{2}=0.03, p<0.001$ ) and soil origin (origin*root treatment $\mathrm{R}^{2}=0.03, \mathrm{p}=0.042$ ). The overall plant root system effects were minor compared to soil properties, nevertheless significant effects of root systems in certain soils were observed (Table 5). The effect of root system type was context-specific: in the non-inoculated control soil both bacterial and fungal communities were significantly affected ( $\mathrm{p}=0.013$ and 0.012 respectively), while for the field-sampled soils root system significantly influenced fungal communities only in arable soil non-inoculated $(\mathrm{p}=0.001)$ and inoculated with woodland soil $(\mathrm{p}=0.015)$. In contrast, inoculation affected both bacterial and fungal communities $(\mathrm{p}<0.05)$ for all combinations of treatments.

The dbRDA constrained ordinations of bacteria and fungi species matrices showed that the main factors affecting the structure of microbial communities were MWD, RMD and soil C:N for bacterial communities and MWD, soil C, RMD, GRSP ${ }_{\mathrm{T}}$ and ergosterol for fungal communities (Fig. 8b). ANCOVA tests performed on the final constrained ordination confirmed that the first two axes, the environmental variables and the final constrained ordination were significant. Bacterial and fungal alpha diversities did not show significant correlations with any of the variables measured (Table S6). Bacterial beta diversity was positively correlated $\left(\mathrm{p}<0.001\right.$ and $\left.\mathrm{R}^{2} \geq 0.3\right)$ with some soil properties (SOC, N, C, GRSP $\mathrm{EE}_{\mathrm{E}}$ and MWD) and with root $\mathrm{N}$, and negatively correlated with soil $\mathrm{pH}$, soil C:N, $\mathrm{CaCO}_{3}$ and root $\mathrm{C}: \mathrm{N}$. Fungal beta diversity was significantly and negatively correlated $(\mathrm{p}<0.001$ and $\mathrm{R}^{2} \geq 0.3$ ) with soil $\mathrm{pH}$ and $\mathrm{CaCO}_{3}$, but positively correlated with MWD and ergosterol (Table S6). It is interesting to note that GRSP was strongly related to bacterial beta diversity, even more than with fungal beta diversity, lending support to the increasing evidence that GSRP is not solely of AFM fungal origin (Cissé et al., 2020). 
611 Soil aggregate stability (MWD) was significantly affected by soil origin $(\mathrm{p}<0.001)$ and inoculation

$612(\mathrm{p}=0.04)$ but not by root system type (Table 6, Figure 7a). The inoculation increased aggregate

613 stability in the poorly structured control soil, but not in arable and woodland soils (Figure 7a). The

614 effect of inoculation was mainly on macroaggregates and their dispersion (fractions 1-2 mm, 0.5-1

$615 \mathrm{~mm}$ and 0.1-0.2 mm; Table S5). The ANCOVA model including RLD showed that the effect of root

616 system type was again not significant, but a significant interaction did occur between inoculation and

617 RLD, revealing that the number of roots modified the effect of inoculation $(p<0.001$; Table 6$)$. The

618 correlations between aggregate stability and the reputed fungal markers $\mathrm{GRSP}_{\mathrm{T}}, \mathrm{GRSP}_{\mathrm{EE}}$ and

619 ergosterol were only significant when all three soils were analysed together (Fig. S4), in agreement

620 with the results of ANOVA tests that showed that only the effect of soil origin was significant (Table

621 S5). The analysis of the textural properties of soil aggregates used for the aggregate stability tests

622 showed that removing the top $15 \mathrm{~mm}$ after the experiment for all soil analyses was efficient and there

623 was no possible influence of soil addition on the results of stability tests (Fig. S5a and S5b), since the

624 texture of aggregates used for the tests was related to origin $(\mathrm{p}=0.001)$ but not to inoculation

$625 \quad(p=0.015$, Fig. S5c).

626 
Hypothesis 1: There are strong relationships between soil aggregate stability and microbial community structure that are driven by land use.

In agreement with our first hypothesis, the impact of land use significantly affected soil aggregate stability and the structure of microbial communities. A large body of previous research has found that the conversion of natural forest to cropland results in a decline of soil quality, SOC and aggregate stability and the opposite is true for soils restored after a disturbance (Barto et al., 2010; Duchicela et al., 2013; Delelegn et al., 2017). Positive relationships between SOC and aggregate stability have been found in different soil types, such as black soils (Zhang et al., 2012), Typic Ustochrepts (Saha et al., 2011), and loamy soils (Vermic Haplubrepts) where SOC is thought to increase aggregate stability by lowering the wettability and increasing the cohesion of aggregates (Chenu et al., 2000). Thus, differences in SOC might explain the lowest aggregate stability in the arable field and the highest stability in pasture and grassland. Apart from this influence of SOC on MWD, we found other factors influencing MWD in our land use gradient that impact aggregate stability, as described previously: i) agricultural practices such as the mechanical action of tillage (Balesdent et al., 2000), management inputs (e.g. fertilizer, herbicide (Steenwerth et al., 2002)) and grazing (Barto et al., 2010), ii) the presence of roots (measured through RLD; Hudek et al. (2017)), iii) the higher C:N in roots and litter implying a higher content in recalcitrant matter that influences fungal activity and MWD as a consequence (Bossuyt et al., 2001).

We demonstrated a strong impact of land use gradient on the structure of bacterial and fungal communities. A regional study in Great Basin Province (California, USA) identified that agricultural management can have larger effects on soil microbial communities than elevation and precipitation gradients (Drenovsky et al., 2010). However, fungal and bacterial communities differ in their responses to changes in agricultural practices. Previous research has shown that tillage reduces microbial biomass and abundance of AMF (Helgason et al., 2010; Zhang et al., 2013) and that the structure of the microbial communities responds strongly to land use with higher proportions of fungi 
observed in natural ecosystems compared with agro-systems (Fanin and Bertrand, 2016). In a study across a range of European field sites, land use intensification effects on microbial communities were stronger when land use change affected soil conditions such as $\mathrm{pH}$, carbon, nitrogen and phosphorous contents (Thomson et al., 2015). Here, although we found significant relationships between the changes in microbial community structure, aggregate stability and soil properties along the land use gradient, causality cannot be confirmed.

\section{Hypothesis 2: The arable field site with lower aggregate stability will have a lower relative} abundance of copiotrophic communities and reduced relative abundances of saprotrophic and ectomycorrhizal fungi, but the rhizosphere niche will favour copiotrophic bacterial communities.

Given that microaggregates are considered to hold oligotrophic communities and macroaggregates favour copiotrophic communities due to their differences in contents of labile/recalcitrant carbon (Trivedi et al., 2017), we expected to find an increase in the relative abundance of copiotrophic communities in soils with higher soil aggregate stability (i.e. higher MWD after disruption). In line with this hypothesis, the arable field (with the lowest soil aggregate stability), had a lower relative abundance of copiotrophic Proteobacteria phyla. However, we did not observe similar trends for copiotrophic Actinobacteria and Bacteroidetes, and oligotrophic Acidobacteria, Chloroflexi and Verrucomicrobia. In addition, correlations between relative abundance of bacterial phyla and MWD were not significant. However, other soil physicochemical factors and notably root and litter physicochemical traits, affected the relative abundance of these phyla with a differential effect on bulk and rhizosphere niches. Lauber et al. (2008) also showed that rather than land use itself, changes in soil edaphic properties explained changes in life strategies of bacterial communities. Since Chloroflexi and Verrucomicrobia were correlated to root and litter physicochemical variables in the rhizosphere but not in the bulk soil, we conclude that oligotrophic bacteria are more dependent on rhizosphere conditions where labile carbon originates mostly from rhizodeposits, exudates and mucigel (Dennis et al., 2010). On the contrary, copiotrophic phyla were more dependent on bulk soil conditions where there are more exopolysaccharides released into the soil by the microorganisms themselves. The relative abundance of these copiotrophic phyla was correlated with some soil 
physicochemical traits ( $\mathrm{pH}, \mathrm{P}$, sand content) and for the specific case of Actinobacteria, this phylum showed correlations with root and litter traits (SRL, RMD, root N, C:N and hemicellulose and litter fibres, Table 2). This particular behaviour of Actinobacteria could be because Actinobacteria exhibits both copiotrophic and oligotrophic life strategies consistent with their capacity to degrade both labile and complex carbon substrates (Ho et al., 2017). Bergmann et al. (2011) found that Verrucomicrobia are oligotrophic with a highly variable relative abundance across soils, and that members of this phylum were most abundant in soils from grasslands and prairies. However, these authors acknowledged that the ecology of Verrucomicrobia remains poorly understood, and different factors may affect the distribution of this phylum.

Studies of bacterial communities inhabiting the rhizosphere in grasslands (Mao et al., 2014; Shi et al., 2015) and croplands (Peiffer et al., 2013; Donn et al., 2015) found that rhizosphere samples are enriched in Proteobacteria, Actinobacteria, and Bacteroidetes. However, here we found an enrichment of Verrucomicrobia (oligotrophic) and diminution of Bacteroidetes (copiotrophic) and Acidobacteria (oligotrophic) in rhizosphere communities. Thus, the hypothesis that the rhizospheric niche favours copiotrophic bacterial taxa (Peiffer et al., 2013; Lladó and Baldrian, 2017) was only confirmed with the reduced relative abundance of the oligotrophic Acidobacteria, highlighting the heterogeneous nature of the rhizosphere and the importance of studying the relationships between soil, root and physicochemical variables and the relative abundance of trophic modes in both rhizosphere and bulk soils that are detailed above.

Fungal symbiotrophs and saprotrophs are among the most sensitive to management practices (Hartmann et al., 2012; Orgiazzi et al., 2012; Mueller et al., 2016). For example, Orgiazzi et al. (2012) found that ectomycorrhizal phylotypes were numerous in natural sites with trees but were missing in anthropogenic and grass-covered sites, whereas Lauber et al. (2008) found that coprophilous fungi were common in grazed sites. Management disturbances have been found to increase the relative abundance of Ascomycota and decrease Basidiomycota (Thomson et al., 2015). Similarly, we observed the expected decrease in fungal saprotrophs and symbiotrophs at the arable site and a higher 
relative abundance of Ascomycota, although a large proportion of unidentified trophic modes may be influencing our results.

Hypothesis 3: Microbial inoculation of soils and dense root systems increase soil aggregate stability in unstructured soils.

Inoculation of live soil communities had large impacts on the sterilised soil communities, irrespective of soil origin (sterilised control, arable or woodland). However, the effect of the inoculation on the structure of bacterial communities was dependent on the origin of the soils. This result agrees with previous studies that found that texture and pore size distribution strongly determined the fate of introduced microorganisms (Rutherford and Juma, 1992; Huysman and Verstraete, 1993; van Veen et al., 1997). Additionally, the effect of root system type was only evident on bacterial communities in the rhizosphere, but not on communities inhabiting bulk soil, which is likely due to differences in root length and the increased microbial numbers in the rhizosphere carbon rich habitat (Jones et al., 2009). In a previous study, we also found that the interactions between microbial community structure and root traits were more intense in communities isolated from rhizosphere compared to bulk soil, and that bacterial community composition was better explained by root traits than in fungal communities (Merino-Martín et al., 2020). We showed that root system type only affected the structure of bacterial communities in control soils that were not inoculated, stressing that the role of roots was secondary compared to inoculation and initial soil structure. Correspondingly, root system type affected fungal community structure in non-inoculated control soil, but it also affected significantly the noninoculated arable soil and arable soil with woodland inoculum, which may be because it had the lowest relative abundance of fungal communities and the least developed mycorrhizal networks. These limited effects of root system type are in agreement with other studies that proposed a hierarchy in the contribution of soils and root systems (traits and exudates), with soil physicochemical properties contributing most strongly to the microbiome and root traits and exudates gradually altering this soil microbiome (Bever et al., 2012; Philippot et al., 2013; van der Putten et al., 2013).

As hypothesized, the microbial inoculation with soils increased aggregate stability in the poorly structured control soil, but not in arable (with low aggregate stability) and woodland soils (with high 
aggregate stability). This finding is in line with Barto et al. (2010), who concluded that, in highly aggregated soils, abiotic factors can be more important for determining soil aggregation than biotic factors. However, besides the lack of initial structure, the control soil also showed very distinct physicochemical properties that can influence the effect of microbial inoculation on aggregate stability, such as lower contents of SOC and soil N, and higher $\mathrm{pH}$ and $\mathrm{CaCO}_{3}$ content (Al-Ani and Dudas, 1988; Chenu et al., 2000; Wu et al., 2017). Even though the focus of our research was on bacterial and fungal communities, we acknowledge that our soil inoculation method may have included soil fauna, such as nematodes, protozoa, or collembolans that were not explored in our study (van de Voorde et al., 2012).

\section{Hypothesis 4: A greater effect of inoculation on aggregate stability is expected in soils inoculated} with woodland soil.

Surprisingly, we did not observe greater aggregate stability in soil inoculated with woodland compared to arable soil. These two soils, woodland and arable, were intrinsically similar but with significantly different aggregate stability. In a similar experiment, Duchicela et al. (2012) found greater stable aggregates in pots inoculated with soil communities from remnant grasslands, compared to soils inoculated with communities from disturbed post-agricultural sites. These authors suggested that the use of the same suite of native prairie plant species across both remnant and disturbed soils in their experiment could explain this effect, reflecting local coadaptation (Duchicela et al., 2012).

Furthermore, the effects of inoculation may also depend on the starting point, the incubation time and conditions after inoculation and not only on the inoculum used.

Several laboratory inoculation experiments also revealed that mycorrhizal fungi play an important role in stabilizing aggregates. Harris et al. (1964) found that even if bacteria were more important than fungi in the primary stabilization of microaggregates, fungi were involved in the stabilization of macroaggregates. Bearden and Petersen (2000) found that AM fungi contributed to the stabilization of aggregates in a vertisol, and that the effect was significant after only one growing season. Bossuyt et al. (2001) found that macroaggregate formation was positively influenced by fungal activity but was not significantly influenced by residue quality or bacterial activity. Most of these inoculation studies 
found that the mechanism by which mycorrhizal fungi increase the stability of aggregates is not only related to hyphae formation, but is also through the stimulation of root growth (Bearden and Petersen, 2000; Graf and Frei, 2013; Bast et al., 2016). In agreement with these authors, we found that in the model including root length density (RLD), there was an effect of the interaction between the inoculation treatment and RLD on aggregate stability, which was remarkable, given the absence of the effect of root type.

We did not observe any effect of inoculation and root system type on the content of glomalin related soil proteins (GRSP) or ergosterol. A significant correlation between these compounds and aggregate stability was found, but it was driven by the different origins of the soils. The legacy effect of soil origin on these compounds emphasizes their recalcitrant nature that has been widely discussed in previous research (Lorenz et al., 2007; Gispert et al., 2013a; Cissé et al., 2020). In addition, GRSP does not appear to be a good predictor of fungal activity, nor of increased physical stability.

\section{Conclusions}

Our results, from field and experimental approaches, depict the complex relationships between soil properties, land use and plant traits shaping microbial communities and affecting soil structure. Our field study demonstrated the existence of strong relationships between land use, microbial communities and soil aggregate stability. Even though we did not find consistent relationships between land use gradient, aggregate stability and the relative abundance of specific bacterial trophic modes, the importance of root traits shaping the relative abundance of bacterial phyla was demonstrated. Rhizosphere conditions shaped bacterial communities with oligotrophic bacteria conditioned by the rhizospheric environment, where labile $\mathrm{C}$ is found, whilst copiotrophic phyla were more dependent on bulk soil conditions. Fungal communities responded to the land use gradient with a lower relative abundance of saprophytic and symbiotic in disturbed sites. The inoculation experiment showed that microbial inoculation affects aggregate stability in the control soil (that had very low aggregate stability initially), but not in soils sterilized from the arable field and the secondary woodland, possibly because in aggregated soils, abiotic factors can be more important for 
786 determining soil aggregation than biotic factors. We did not observe differential effects of the

787 different inoculums (arable versus secondary woodland), most likely due to the short period of the

788 inoculation experiment. Again, the importance of roots for bacterial communities in the rhizosphere

789 niche was highlighted in the inoculation experiment, with root system type affecting only the structure

790 of bacterial communities but not fungal communities, and only in the rhizosphere but not in bulk

791 soils. Additionally, root system type only affected the structure of bacterial communities in control

792 soils that were not inoculated, stressing that the role of roots was secondary compared to inoculation

793 and initial soil structure. Finally, even though we did not find a significant effect of root system type

794 on aggregate stability, we have shown that the effect of the microbial inoculation was modulated by

795 root length density, highlighting the role of roots in shaping microbial communities and their effects

796 on soil structure. 
798 LMM and this research were funded with a Marie Curie IEF fellowship (FP7 European program, ref.

799 626666/2013). Many thanks to Francois Pailler, Clément Furget-Bretagnon (INRAE France), Jean

800 Marc Souquet and Josiane Abadie (UMR Eco\&Sols, Montpellier) for their help with laboratory work.

801 Thanks are due to Oxford University and FAI Farms, U.K. (FAI Field Station) for access to field sites.

802 A major part of this paper was written by the first author in Madrid, Spain, during the COVID-19

803 lockdown. The authors would like to thank health workers in Spain and worldwide, who risked their

804 lives to overcome the pandemic. 
806 Table 1. Soil physicochemical properties of sites selected for the field study (mean of the six samples 807 collected at depths of 0-0.1 m and 0.2-0.3 m). Sand, silt, clay, soil organic carbon (SOC), total 808 nitrogen $(\mathrm{N})$ and total carbon $(\mathrm{C})$ are expressed in \% w/w. Available $\mathrm{P}, \mathrm{K}$ and $\mathrm{Mg}$ are expressed in $809 \mathrm{mg} / \mathrm{l}$. Carbon:nitrogen $(\mathrm{C}: \mathrm{N})$ ratio is expressed in :1. F and $\mathrm{p}$ values are shown. Post hoc comparisons

\begin{tabular}{|c|c|c|c|c|c|c|c|}
\hline & $\begin{array}{c}\text { Ancient } \\
\text { Woodland }\end{array}$ & $\begin{array}{l}\text { Secondary } \\
\text { Woodland }\end{array}$ & Grassland & Pasture & Arable & F value & $\operatorname{Pr}(>\mathrm{F})$ \\
\hline $\mathrm{pH}$ & $\begin{array}{c}5.87 \pm 0.16 \\
a\end{array}$ & $\begin{array}{c}6.38 \pm 0.15 \\
a b\end{array}$ & $\begin{array}{c}6.30 \pm 0.15 \\
a\end{array}$ & $\begin{array}{c}6.10 \pm 0.06 \\
a\end{array}$ & $\begin{array}{c}7.00 \pm 0.22 \\
b\end{array}$ & 7.376 & $<0.001$ \\
\hline $\mathbf{P}$ & $\begin{array}{c}12.73 \pm 2.44 \\
a\end{array}$ & $\begin{array}{c}10.50 \pm 2.53 \\
a\end{array}$ & $\begin{array}{c}14.10 \pm 2.03 \\
a\end{array}$ & $\begin{array}{c}20.07 \pm 2.38 \\
a\end{array}$ & $\begin{array}{c}80.47 \pm 2.47 \\
b\end{array}$ & 157.2 & $<0.001$ \\
\hline K & $\begin{array}{c}321.17 \pm 28.01 \\
a\end{array}$ & $\begin{array}{c}253.50 \pm 41.88 \\
a\end{array}$ & $\begin{array}{c}254.67 \pm 29.70 \\
a\end{array}$ & $\begin{array}{c}205.67 \pm 15.24 \\
a\end{array}$ & $\begin{array}{c}595.00 \pm 49.26 \\
b\end{array}$ & 19.99 & $<0.001$ \\
\hline Mg & $\begin{array}{c}256.33 \pm 10.19 \\
b\end{array}$ & $\begin{array}{c}247.50 \pm 5.91 \\
a b\end{array}$ & $\begin{array}{c}229.50 \pm 7.10 \\
a b\end{array}$ & $\begin{array}{c}222.50 \pm 5.46 \\
a b\end{array}$ & $\begin{array}{c}209.00 \pm 16.65 \\
a\end{array}$ & 3.661 & 0.018 \\
\hline Sand & $\begin{array}{c}35.00 \pm 2.85 \\
\text { ac }\end{array}$ & $\begin{array}{c}25.67 \pm 2.63 \\
a\end{array}$ & $\begin{array}{c}40.17 \pm 5.31 \\
b c\end{array}$ & $\begin{array}{c}52.67 \pm 2.76 \\
b\end{array}$ & $\begin{array}{c}29.17 \pm 1.47 \\
\text { ac }\end{array}$ & 10.57 & $<0.001$ \\
\hline Silt & $\begin{array}{c}41.50 \pm 1.15 \\
a\end{array}$ & $\begin{array}{c}44.00 \pm 0.52 \\
a\end{array}$ & $\begin{array}{c}38.33 \pm 2.62 \\
a b\end{array}$ & $\begin{array}{c}32.83 \pm 1.58 \\
b\end{array}$ & $\begin{array}{c}40.50 \pm 1.02 \\
a\end{array}$ & 7.416 & $<0.001$ \\
\hline Clay & $\begin{array}{c}23.50 \pm 1.88 \\
a b\end{array}$ & $\begin{array}{c}30.33 \pm 2.28 \\
a\end{array}$ & $\begin{array}{c}21.50 \pm 2.92 \\
a b\end{array}$ & $\begin{array}{c}14.50 \pm 1.23 \\
b\end{array}$ & $\begin{array}{c}30.33 \pm 2.23 \\
a\end{array}$ & 9.331 & $<0.001$ \\
\hline Texture & Clay Loam & Clay Loam & Sandy Loam & Sandy Loam & Clay Loam & - & - \\
\hline SOC & $\begin{array}{c}11.28 \pm 1.34 \\
\text { bc }\end{array}$ & $\begin{array}{c}13.60 \pm 1.38 \\
a b c\end{array}$ & $\begin{array}{c}14.78 \pm 1.37 \\
a b\end{array}$ & $\begin{array}{c}17.43 \pm 1.46 \\
a\end{array}$ & $\begin{array}{c}8.52 \pm 0.29 \\
c\end{array}$ & 7.435 & $<0.001$ \\
\hline Total Nitrogen & $\begin{array}{c}0.46 \pm 0.06 \\
a b\end{array}$ & $\begin{array}{c}0.59 \pm 0.05 \\
a b\end{array}$ & $\begin{array}{c}0.66 \pm 0.05 \\
\text { ac }\end{array}$ & $\begin{array}{c}0.87 \pm 0.06 \\
c\end{array}$ & $\begin{array}{c}0.42 \pm 0.01 \\
b\end{array}$ & 12.76 & $<0.001$ \\
\hline Total Carbon & $\begin{array}{c}5.25 \pm 0.73 \\
b\end{array}$ & $\begin{array}{c}6.52 \pm 0.74 \\
a b\end{array}$ & $\begin{array}{c}6.97 \pm 0.68 \\
a b\end{array}$ & $\begin{array}{c}8.56 \pm 0.75 \\
a\end{array}$ & $\begin{array}{c}4.36 \pm 0.12 \\
b\end{array}$ & 6.202 & $<0.001$ \\
\hline C:N & $\begin{array}{c}11.18 \pm 0.25 \\
a\end{array}$ & $\begin{array}{c}11.02 \pm 0.40 \\
a\end{array}$ & $\begin{array}{c}10.42 \pm 0.30 \\
a\end{array}$ & $\begin{array}{c}9.85 \pm 0.18 \\
a\end{array}$ & $\begin{array}{c}10.52 \pm 0.46 \\
a\end{array}$ & 2.51 & 0.067 \\
\hline
\end{tabular}


812 Table 2. Spearman's correlation coefficients between relative abundance of the different phyla of

813 Bacteria and soil properties, root and litter traits for bulk soil and rhizosphere sample fractions in the

814 field study $(* * * * \mathrm{P}<0.0001, * * * \mathrm{P}<0.001, * * \mathrm{P}<0.01, * \mathrm{P}<0.05)$. Correlations $\geq 0.65$ are

815 highlighted in bold and correlations present in only one sample fraction are highlighted in red.

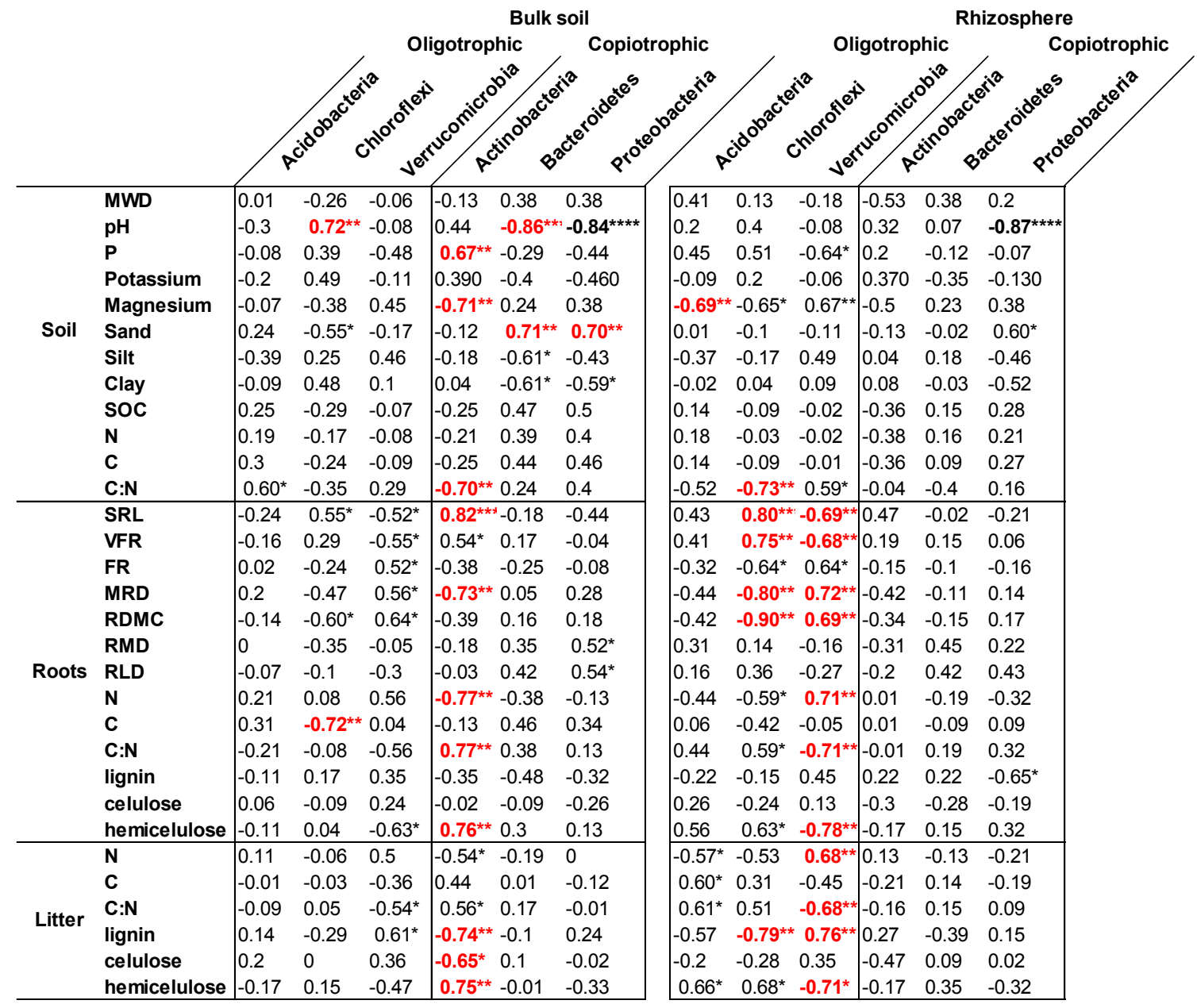

817 Table 3. Effects of land use and sample fraction and their interactions on the structure of bacterial and

818 fungal communities assessed with PERMANOVA. The degrees of freedom (Df), sum of squares (sum

819 of sqs), mean of squares (mean of sqs), the F. statistic, the proportion of the variance explained by

820 each model $\left(\mathrm{R}^{2}\right)$ and probability $(\mathrm{P})$ are shown.

\begin{tabular}{|c|c|c|c|c|c|c|c|c|c|c|c|c|}
\hline \multirow[b]{2}{*}{ Factors } & \multirow[b]{2}{*}{ Df } & \multicolumn{5}{|c|}{ Bacteria } & \multicolumn{6}{|c|}{ Fungi } \\
\hline & & $\begin{array}{c}\text { Sums of } \\
\text { sqs }\end{array}$ & $\begin{array}{c}\text { Mean of } \\
\text { sqs }\end{array}$ & F.Model & $\mathbf{R}^{2}$ & $\operatorname{Pr}(>F)$ & Df & $\begin{array}{c}\text { Sums of } \\
\text { sqs }\end{array}$ & $\begin{array}{c}\text { Mean of } \\
\text { sqs }\end{array}$ & F.Model & $\mathbf{R}^{2}$ & $\operatorname{Pr}(>F)$ \\
\hline Land use & 4 & 1.5469 & 0.38673 & 4.4095 & 0.438 & 0.001 & 4 & 4.8003 & 1.20008 & 6.3216 & 0.533 & 0.001 \\
\hline Samplefraction & 1 & 0.1366 & 0.1366 & 1.5575 & 0.039 & 0.093 & 1 & 0.1365 & 0.13649 & 0.719 & 0.015 & 0.745 \\
\hline Land use*Samplefraction & 4 & 0.1793 & 0.04483 & 0.5112 & 0.051 & 1 & 4 & 0.4629 & 0.11572 & 0.6096 & 0.051 & 0.993 \\
\hline Residuals & 19 & 1.6663 & 0.0877 & & 0.472 & & 19 & 3.6069 & 0.18984 & & 0.400 & \\
\hline Total & 28 & 3.5292 & & & 1 & & 28 & 9.0067 & & & 1 & \\
\hline
\end{tabular}


821 Table 4. Effects of inoculation, origin and root treatments and their interactions on the structure of

822 bacterial and fungal communities assessed with PERMANOVA. The degrees of freedom (Df), sum of

823 squares (sum of sqs), mean of squares (mean of sqs), the F. statistic, the proportion of the variance

824 explained by each model $\left(\mathrm{R}^{2}\right)$ and probability $(\mathrm{P})$ are shown.

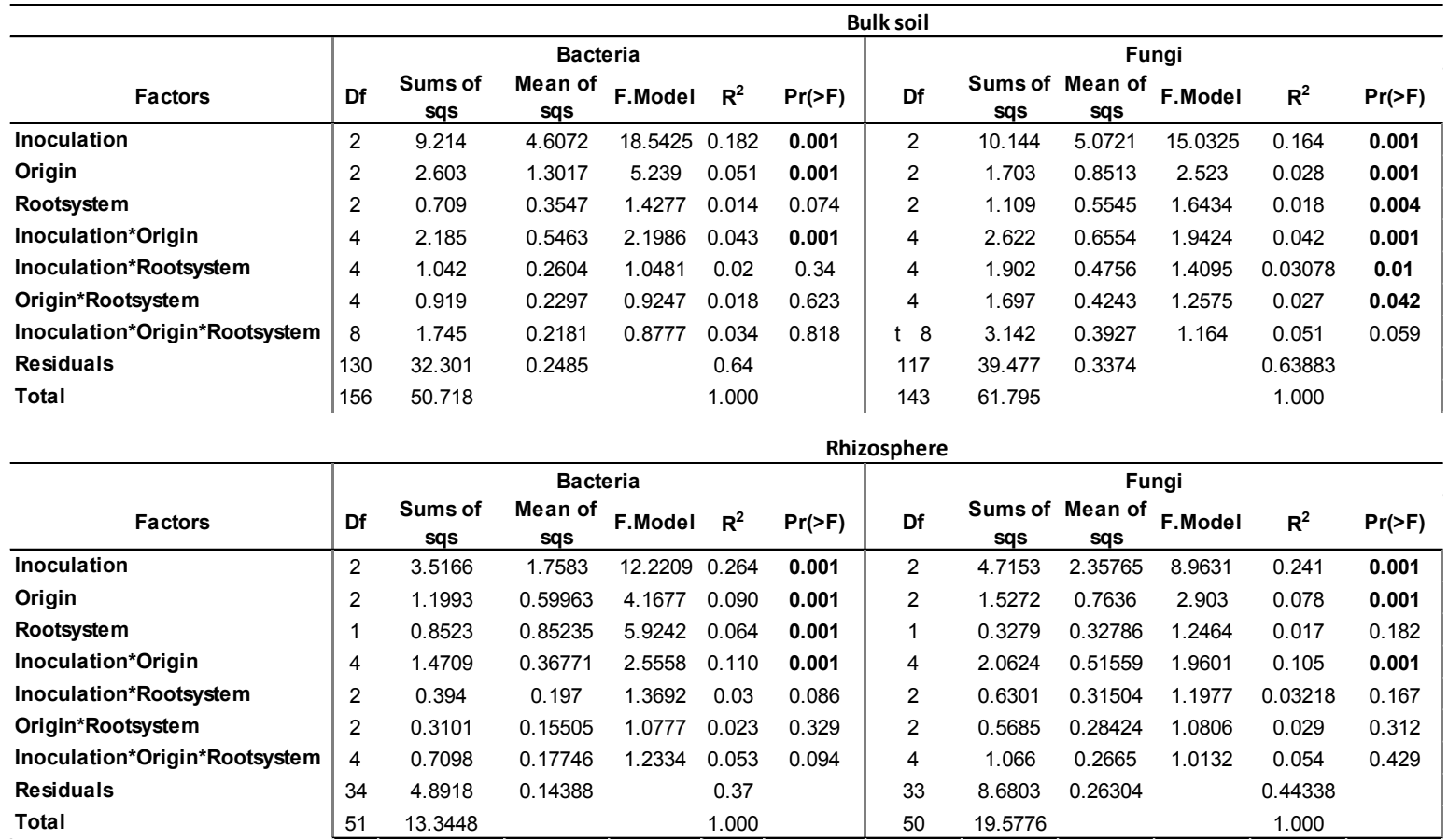

825 
827 Table 5. Effects of root system type and inoculation in each of the combinations of the experimental

828 design. The ANOSIM statistic R and the significance values are shown. The proportion of the

829 variance explained by each model $\left(\mathrm{R}^{2}\right)$ and probability (P) are shown.

\begin{tabular}{|c|c|c|c|c|c|}
\hline \multirow{3}{*}{ Origin } & \multirow{3}{*}{ Inoculation } & \multicolumn{4}{|c|}{ Effect of root system } \\
\hline & & \multicolumn{2}{|c|}{ Bacteria } & \multicolumn{2}{|c|}{ Fungi } \\
\hline & & $\mathbf{R}^{2}$ & $\operatorname{Pr}(>F)$ & $\mathbf{R}^{2}$ & $\operatorname{Pr}(>\mathrm{F})$ \\
\hline Arable & Arable & -0.029 & 0.551 & -0.008 & 0.520 \\
\hline Arable & Notlnoculated & 0.016 & 0.381 & 0.341 & 0.001 \\
\hline Arable & Woodland & 0.005 & 0.398 & 0.251 & 0.015 \\
\hline Control & Arable & -0.080 & 0.818 & -0.075 & 0.797 \\
\hline Control & NotInoculated & 0.172 & 0.013 & 0.687 & 0.012 \\
\hline Control & Woodland & -0.021 & 0.461 & -0.029 & 0.564 \\
\hline Woodland & Arable & -0.047 & 0.624 & 0.019 & 0.355 \\
\hline Woodland & Notlnoculated & 0.108 & 0.121 & 0.056 & 0.213 \\
\hline Woodland & Woodland & 0.013 & 0.367 & -0.004 & 0.483 \\
\hline \multirow{3}{*}{ Origin } & \multirow{3}{*}{ Root system } & \multicolumn{4}{|c|}{ Effect of inoculation } \\
\hline & & \multicolumn{2}{|c|}{ Bacteria } & \multicolumn{2}{|c|}{ Fungi } \\
\hline & & $\mathbf{R}^{2}$ & $\operatorname{Pr}(>F)$ & $\mathbf{R}^{2}$ & $\operatorname{Pr}(>\mathrm{F})$ \\
\hline Arable & Fibrous & 0.460 & 0.001 & 0.709 & 0.001 \\
\hline Arable & Noroot & 0.362 & 0.003 & 0.577 & 0.001 \\
\hline Arable & Tap & 0.398 & 0.004 & 0.753 & 0.001 \\
\hline Control & Fibrous & 0.616 & 0.001 & 0.825 & 0.001 \\
\hline Control & Noroot & 0.501 & 0.002 & 0.798 & 0.001 \\
\hline Control & Tap & 0.505 & 0.002 & 0.497 & 0.001 \\
\hline Woodland & Fibrous & 0.513 & 0.001 & 0.789 & 0.001 \\
\hline Woodland & Noroot & 0.590 & 0.001 & 0.612 & 0.001 \\
\hline Woodland & Tap & 0.563 & 0.001 & 0.820 & 0.001 \\
\hline
\end{tabular}

831

832

833

834

835

836

837 
840 Table 6. Effects of inoculation, soil origin and root system type and their interactions on soil

841 aggregate stability assessed with ANOVA. An additional ANCOVA model was tested including root

842 length density (RLD), to separate the effect of species and physical properties (quantity of roots)

843 within the effect of root system treatment. The degrees of freedom (Df), sum of squares (Sum of sqs),

844 mean of squares (Mean of sqs), the F. statistic and p-value (P) associated with the F statistic are

845 shown.

\begin{tabular}{|c|c|c|c|c|c|}
\hline Factors & Df & $\begin{array}{c}\text { Sums of } \\
\text { sqs }\end{array}$ & $\begin{array}{c}\text { Mean of } \\
\text { sqs }\end{array}$ & F.Model & $\operatorname{Pr}(>F)$ \\
\hline Origin & 2 & 45.76 & 22.881 & 460.529 & $<0.001$ \\
\hline Inoculation & 2 & 0.33 & 0.166 & 3.348 & 0.043 \\
\hline Root system & 2 & 0.07 & 0.033 & 0.656 & 0.523 \\
\hline Origin*Inoculation & 4 & 1.76 & 0.439 & 8.833 & $<0.001$ \\
\hline Origin*Root system & 4 & 0.3 & 0.076 & 1.531 & 0.206 \\
\hline Inoculation*Root system & 4 & 0.06 & 0.016 & 0.318 & 0.865 \\
\hline Origin*Inoculation*Root system & 8 & 0.37 & 0.046 & 0.92 & 0.507 \\
\hline Residuals & 54 & 2.68 & 0.05 & & \\
\hline \multicolumn{6}{|c|}{ Model including RLD } \\
\hline Origin & 2 & 45.76 & 22.88 & 871.82 & $<0.001$ \\
\hline Inoculation & 2 & 0.33 & 0.166 & 6.343 & 0.005 \\
\hline Root system & 2 & 0.07 & 0.033 & 1.246 & 0.302 \\
\hline RLD & 1 & 0.04 & 0.038 & 1.457 & 0.237 \\
\hline Origin*Inoculation & 4 & 1.89 & 0.472 & 17.994 & $<0.001$ \\
\hline Origin*Root system & 4 & 0.24 & 0.059 & 2.264 & 0.085 \\
\hline Inoculation*Root system & 4 & 0.04 & 0.01 & 0.385 & 0.817 \\
\hline Origin*RLD & 2 & 0.01 & 0.006 & 0.22 & 0.803 \\
\hline Inoculation*RLD & 2 & 0.6 & 0.301 & 11.462 & 0.000 \\
\hline Root system*RLD & 2 & 0.04 & 0.019 & 0.707 & 0.501 \\
\hline Origin*Inoculation*Root system & 8 & 0.38 & 0.048 & 1.83 & 0.109 \\
\hline Origin*Inoculation*RLD & 4 & 0.38 & 0.096 & 3.649 & 0.015 \\
\hline Origin*Root system*RLD & 4 & 0.37 & 0.092 & 3.5 & 0.018 \\
\hline Inoculation*Root system*RLD & 3 & 0.31 & 0.104 & 3.955 & 0.017 \\
\hline Origin*Inoculation*Root system*RLD & 5 & 0.06 & 0.011 & 0.43 & 0.824 \\
\hline Residuals & 31 & 0.81 & 0.026 & & \\
\hline
\end{tabular}




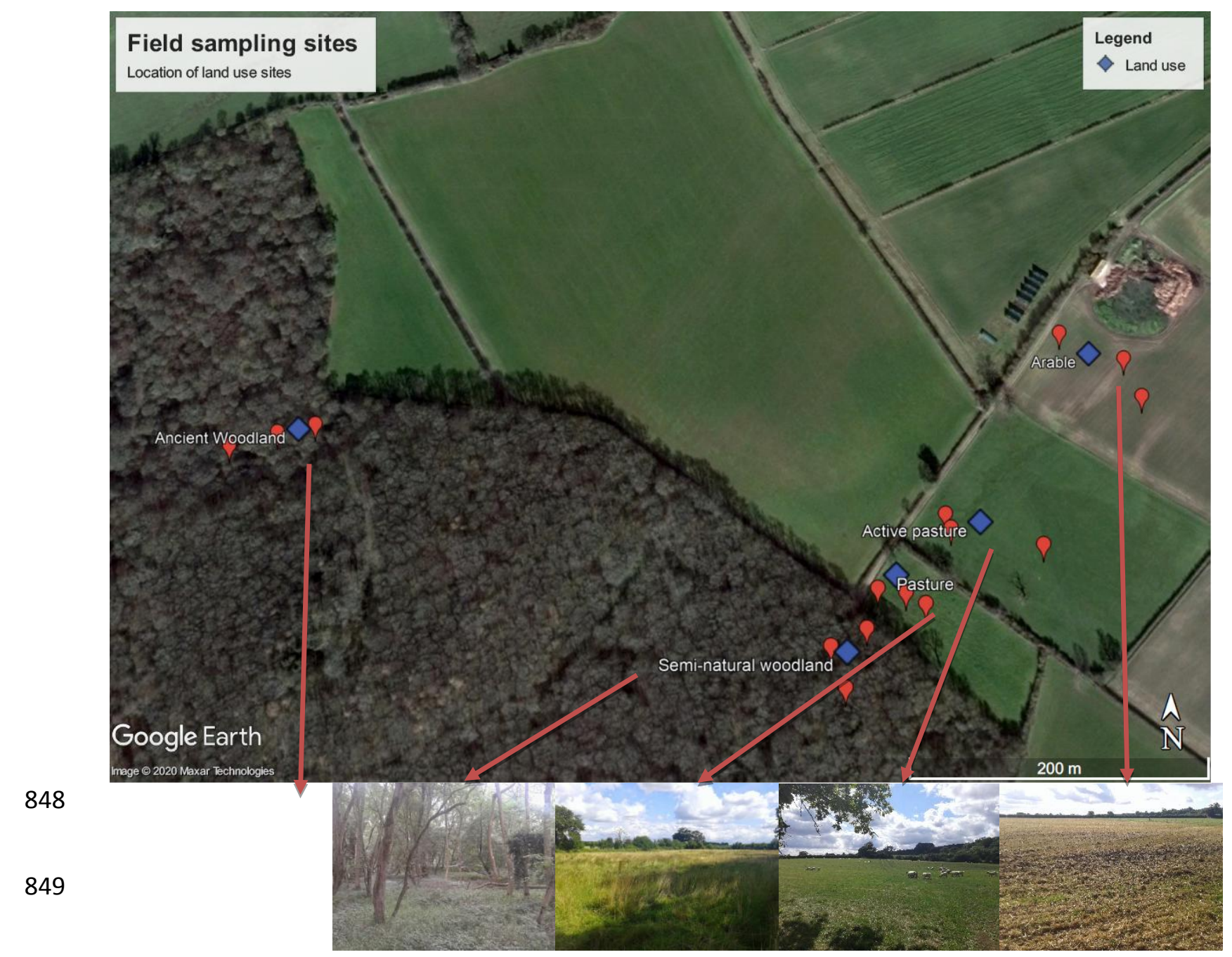

850 Figure 1. Location of sampling plots spanning a range of land uses. Red dots correspond to plots

851 where sampling was performed. (Source: $51^{\circ} 46^{\prime} 46.91^{\prime \prime} \mathrm{N}$ and $1^{\circ} 19^{\prime} 35.76^{\prime \prime}$. Google Earth

852 v7.3.2.5776, May 20, 2018. May 11, 2020). 


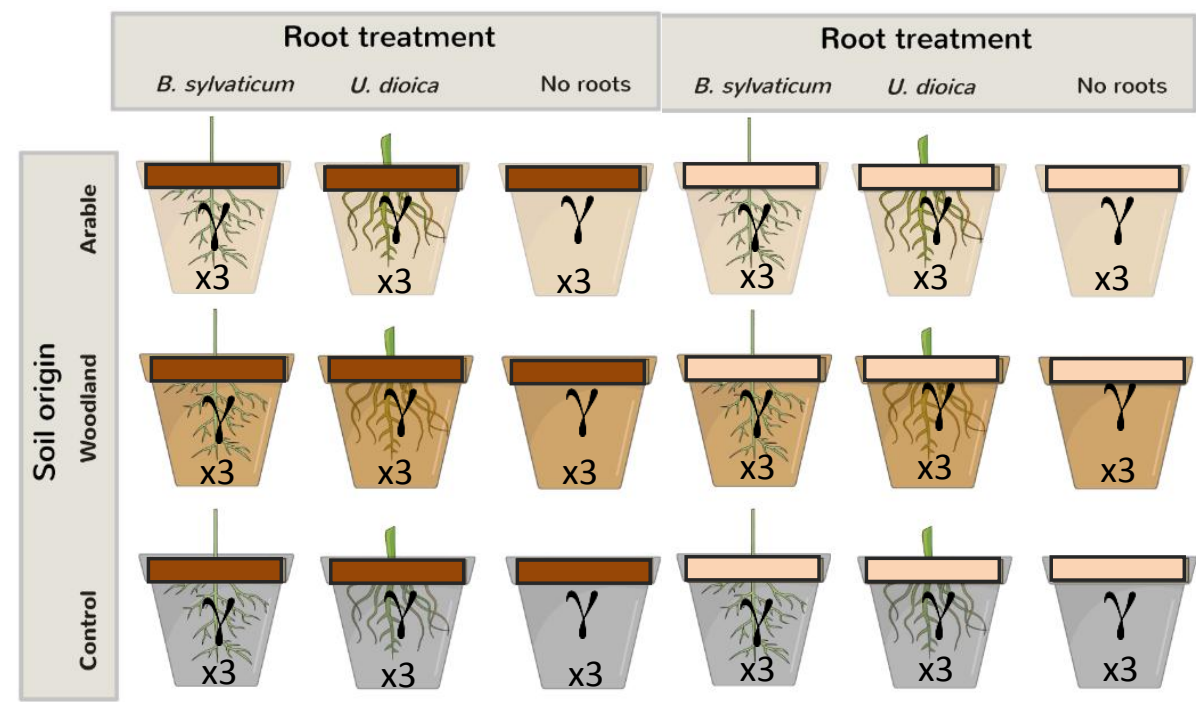

855

856

857

858

859

860
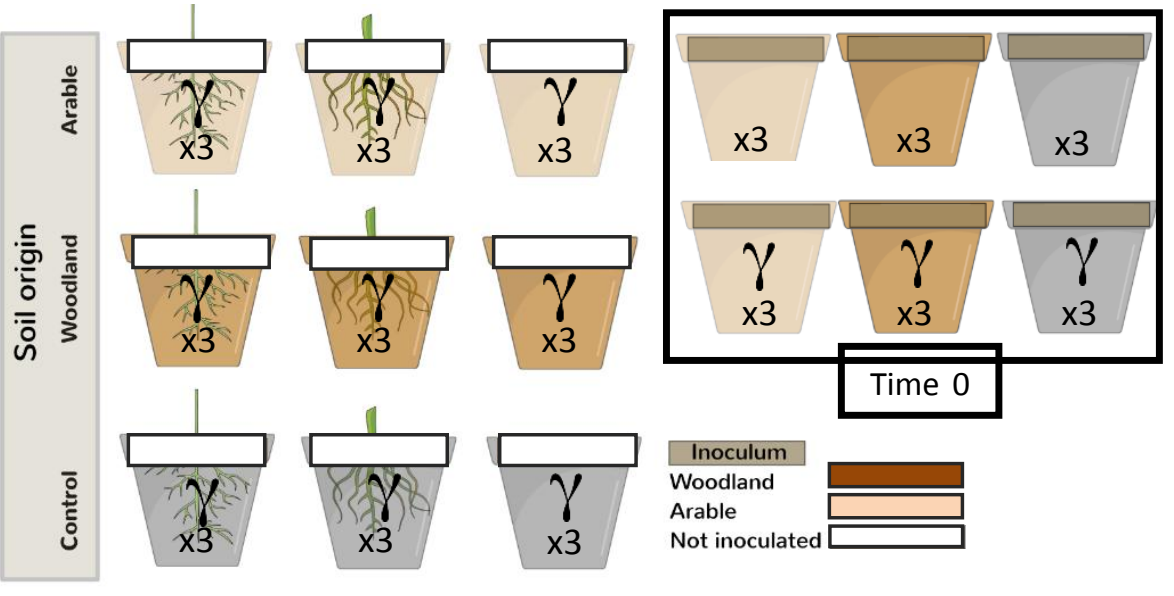

861 Figure 2. Schematic illustration of the treatments under study with three soil origins, three root

862 system types (fibrous root system of Brachypodium sylvaticum, taproot system of Urtica dioca and a control with no roots present) and three inoculation treatments. Different coloured bars on tops of pots refer to the source of soil inoculum (see legend). 


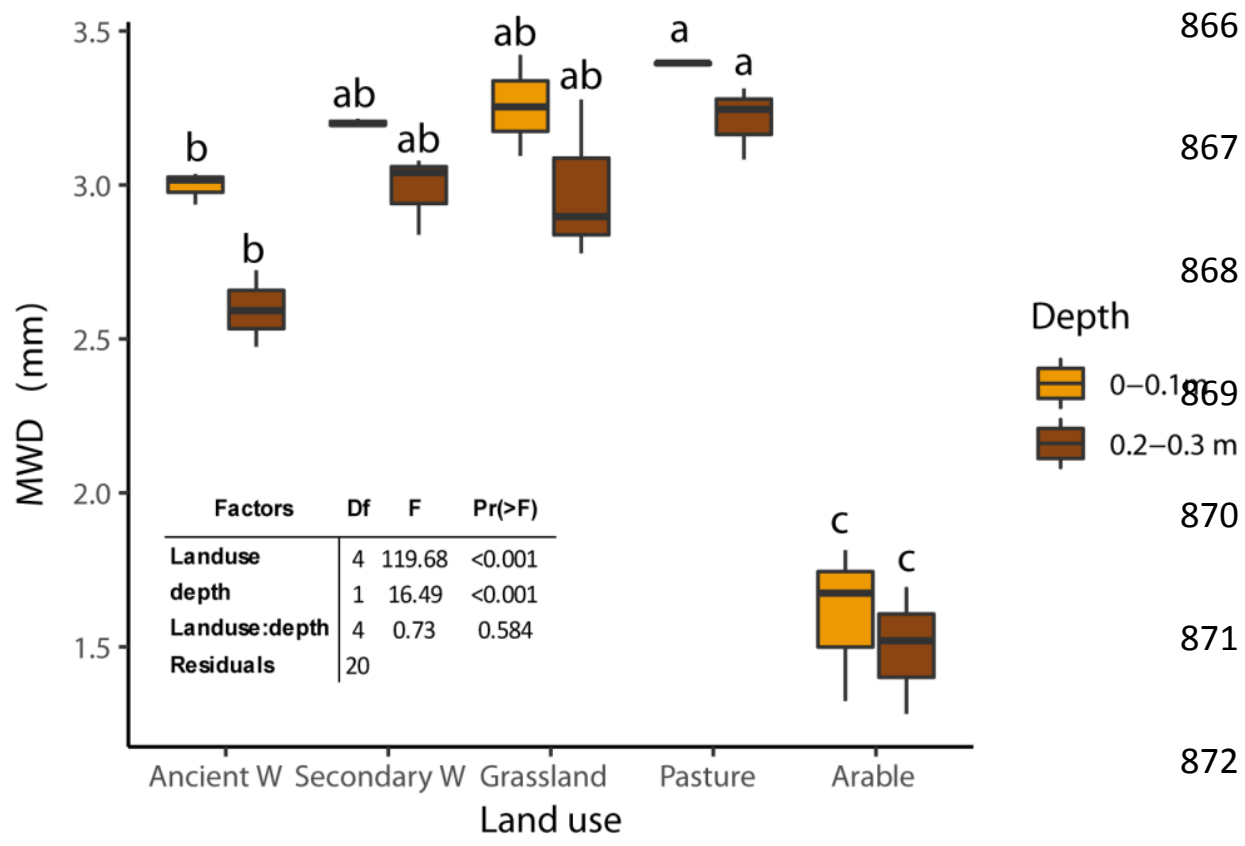

873 Figure 3. Soil aggregate stability (MWD) measured in the field in the different land uses at the

874 surface and $0.2-0.3 \mathrm{~m}$ depth. Boxplots represent the minimum, maximum, median, first quartile and

875 third quartile in the data set. Different letters show post-hoc Tukey honestly significant difference

876 (HSD) results between land uses for the two different depths.

877 
a)

Phylum

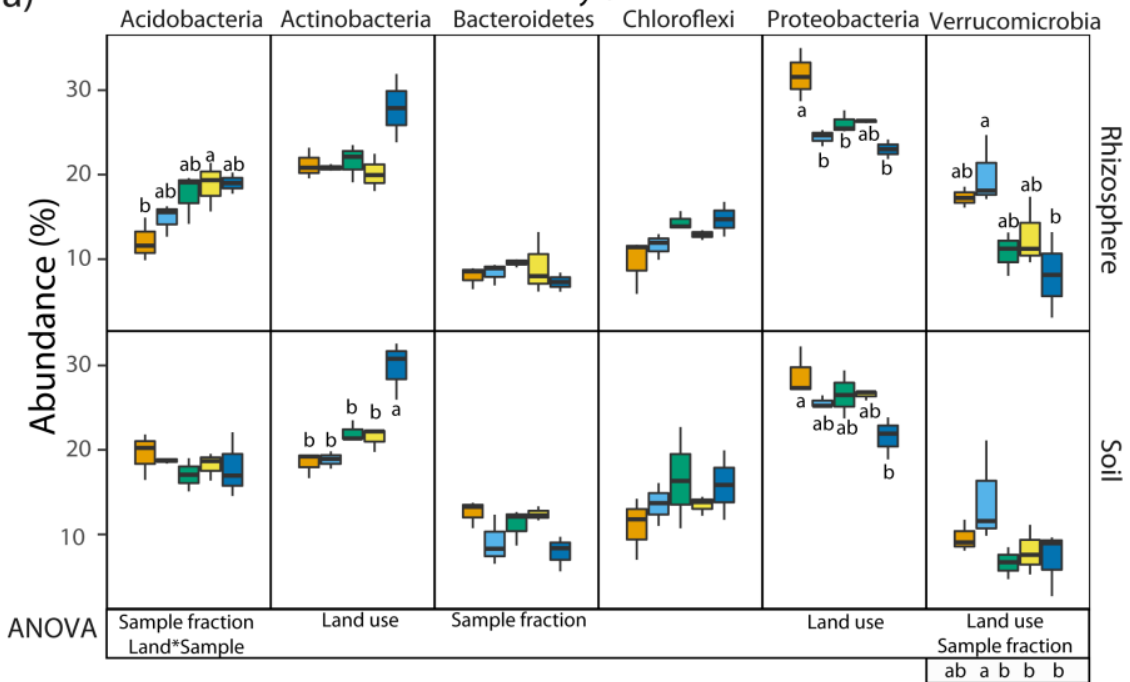

b)

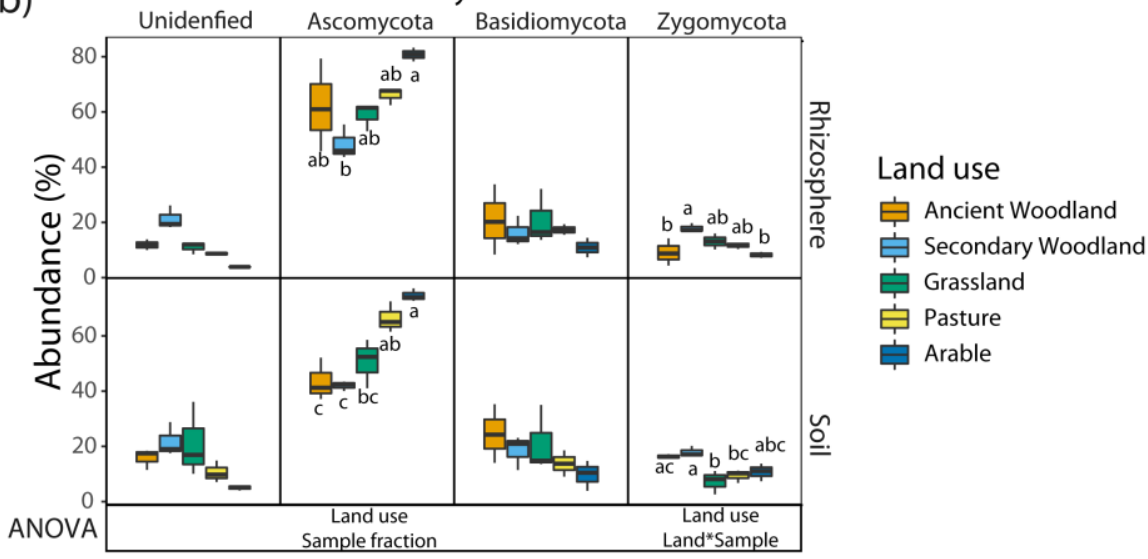

c)

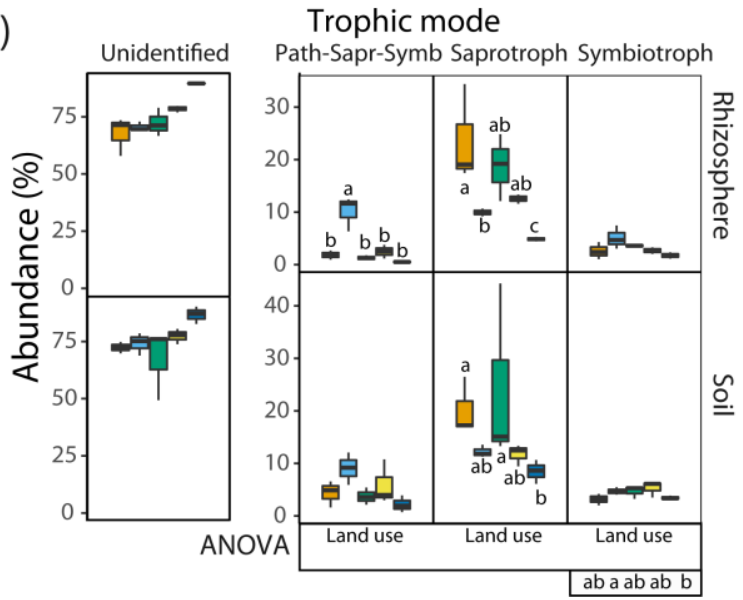

878 Figure 4. Boxplots with relative abundance of phyla found in the three plots in each land use in

879 rhizosphere and bulk soil fractions for bacteria (a) and fungi (b) and proportion of fungal trophic

880 modes (c). Boxplots represent the minimum, maximum, median, first quartile and third quartile in the

881 data set. Different letters show post-hoc Tukey honestly significant difference (HSD) results. Letters

882 out of the boxplot figure show the overall effect including rhizosphere and bulk soils. 
883

884

885

886

887

888

889

890

891

892

893

894

895

896

897

898

899

900

901
Bacteria

a)

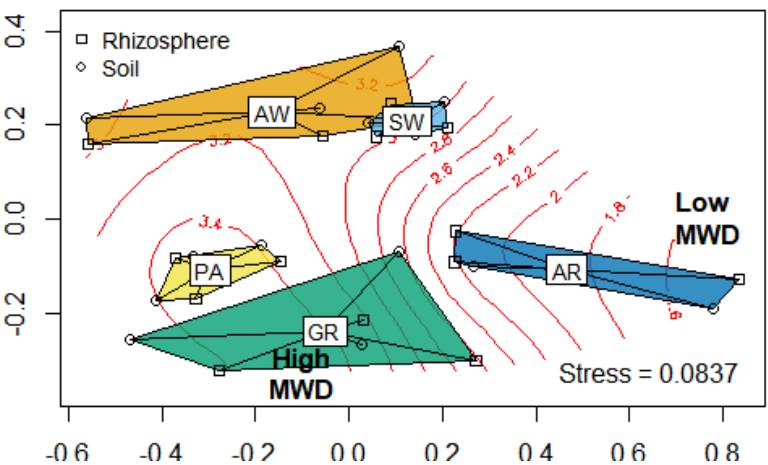

b)

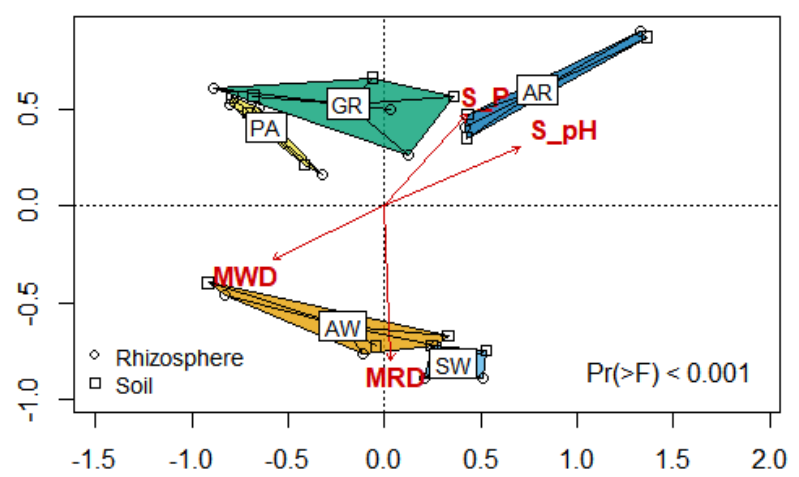

Fungi
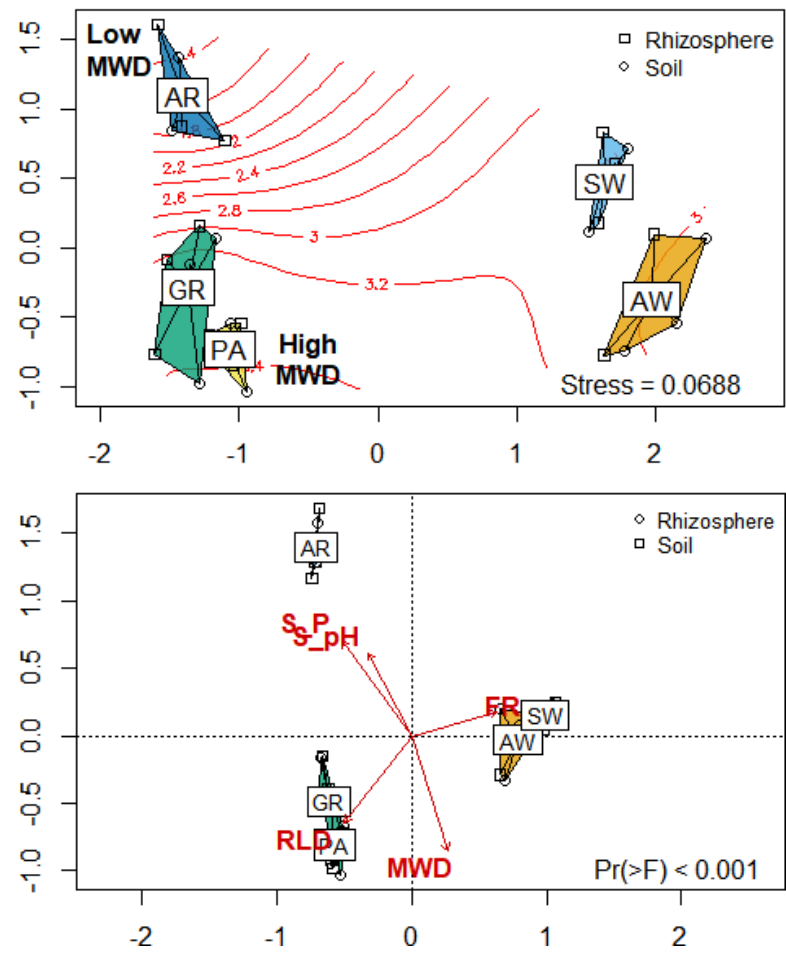

Figure 5. a) NMDS ordinations of bacteria and fungi species matrices with convex hull polygons and spider diagrams containing plots of the five sites and overlaid gradients of aggregate stability and b) graphs of dbRDA constrained ordinations of bacteria and fungi species matrices with convex hull polygons and spider diagrams containing plots of the five sites and significant variables obtained by automatic backward stepwise model building. Data are shown for rhizosphere ( $\square$ ) and bulk soil (०) fractions. Acronyms for land use types: AW isancient woodland, SW is secondary woodland, GR is grassland, $\mathrm{PA}$ is pasture, and AR is arable. Acronyms for factors: $\mathrm{S} \_\mathrm{pH}$ is soil $\mathrm{pH}, \mathrm{S} \_\mathrm{P}$ is soil $\mathrm{P}$, MWD is mean weight diameter, MRD is mean root diameter, FR is \% fine roots, RLD is root length density. 


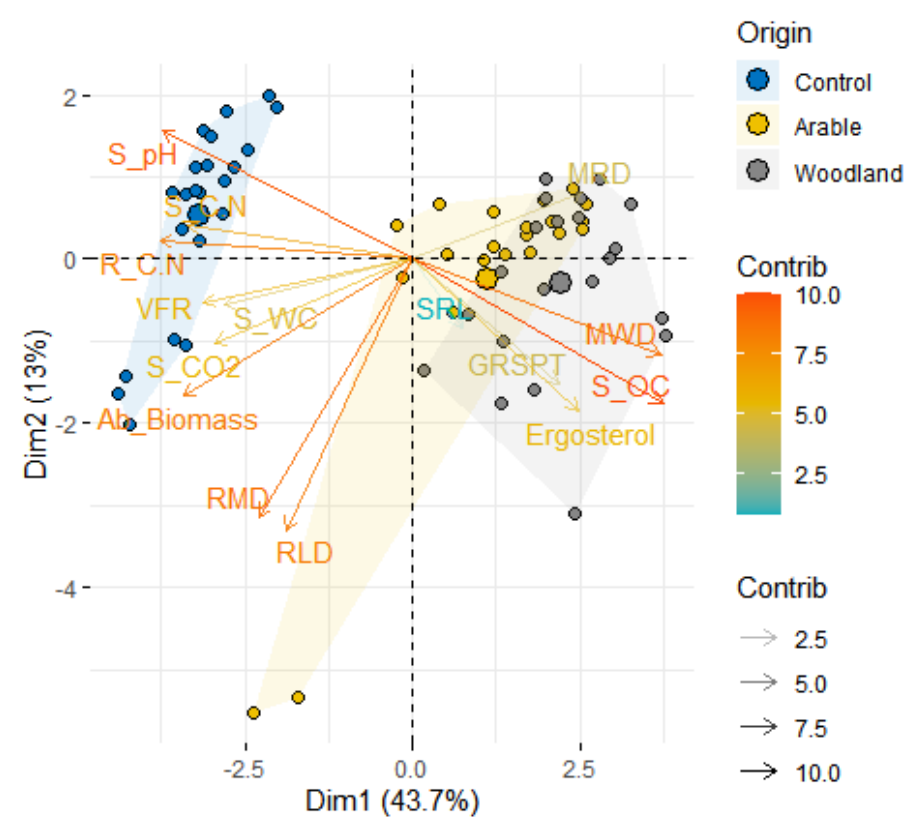

909 Figure 6. PCA of variables used for the description of soil, vegetation and root properties in the

910 experiment. Variables showed were selected based on their correlation and ecological significance

911 (i.e. variables that were correlated but their source was ecologically different were kept, e.g. soil C:N

912 and root $\mathrm{C}: \mathrm{N})$. Acronyms: $\mathrm{S} \_\mathrm{pH}$ is soil $\mathrm{pH}, \mathrm{S} \_\mathrm{C} . \mathrm{N}$ is soil C:N ratio, $\mathrm{S} \_\mathrm{WC}$ is soil water content,

913 S_CO2 is rate of exchange of $\mathrm{CO}_{2}, \mathrm{~S} \_\mathrm{OC}$ is soil organic carbon, MWD is mean weight diameter,

914 Ab_biomass is Aboveground biomass, R_C.N is root C:N ratio, VFR is \% very fine roots, RMD is

915 root mean diameter, RLD is root length density, MRD is mean root diameter, SRL is specific root

916 length, GRSPT is total glomalin related soil proteins. 


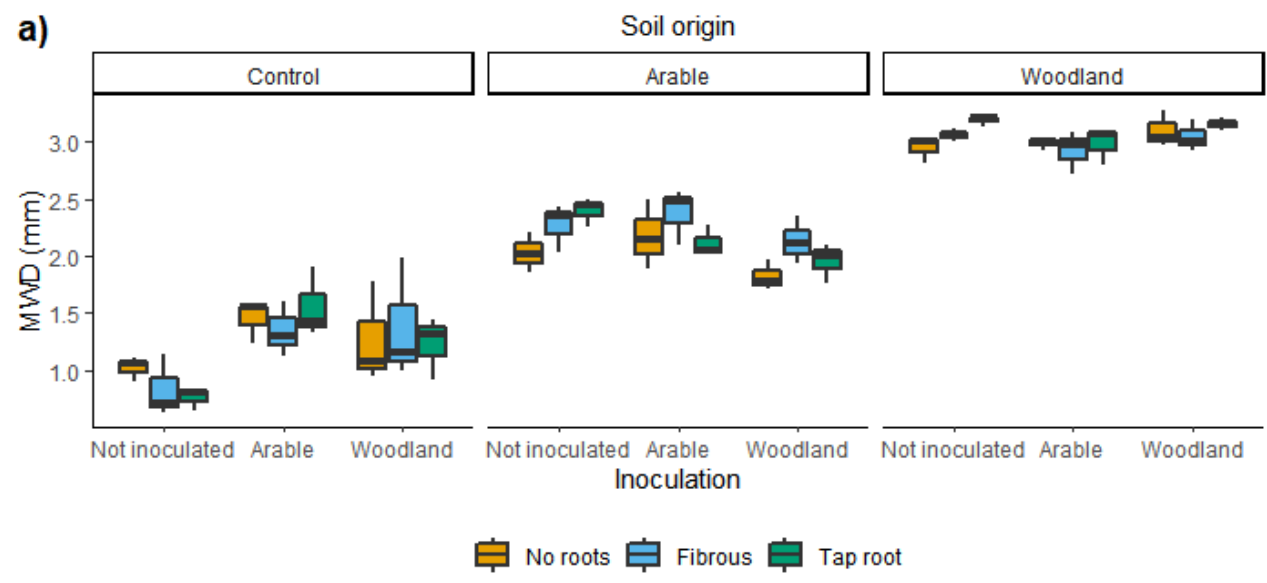

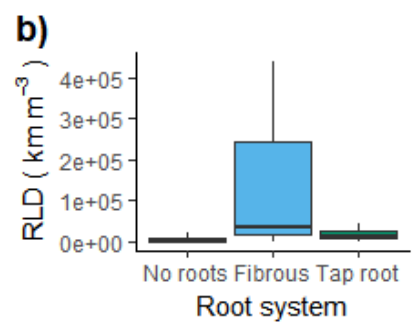

c)
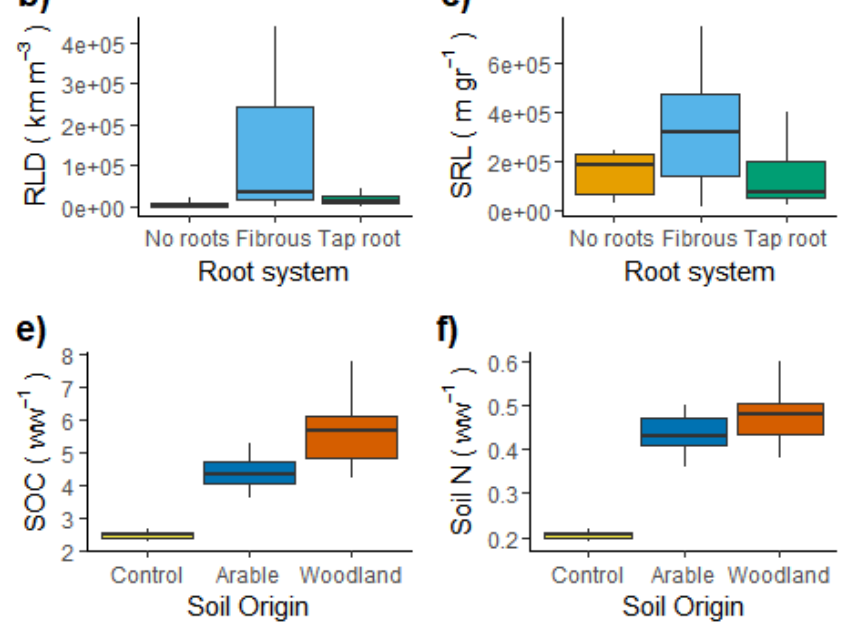

f)

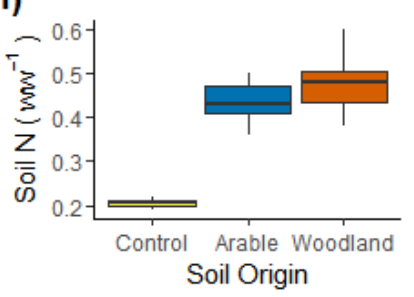

d)

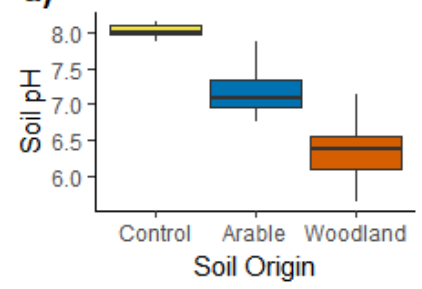

g)

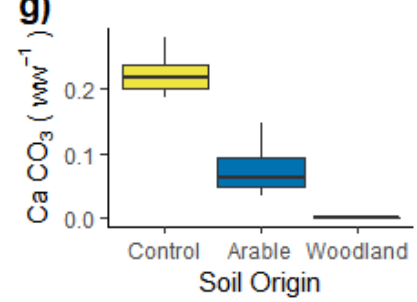

918 Figure 7. Selected specific traits of soil samples after incubation period: a) soil aggregate stability

919 (mean weight diameter, MWD), b) root length density (RLD, $\mathrm{km} \mathrm{m}^{-3}$ ), c) specific root length (SRL, $\mathrm{m}$

$\left.\left.920 \mathrm{gr}^{-1}\right), \mathrm{d}\right)$ soil $\left.\mathrm{pH}, \mathrm{e}\right)$ soil organic carbon $\left.\left(\mathrm{SOC}, \mathrm{ww}^{-1}\right), \mathrm{f}\right)$ soil nitrogen $\left.\left(\mathrm{N}, \mathrm{ww}^{-1}\right), \mathrm{g}\right)$ soil total inorganic

921 carbon $\left(\mathrm{CaCO}_{3}, \mathrm{ww}^{-1}\right)$. Boxplots represent the minimum, maximum, median, first quartile and third

922 quartile in the data set. 
923

924

925

926

927

928

929

930

931

932

933

934

935

936

937

938

939

940

941
Bacteria

a)

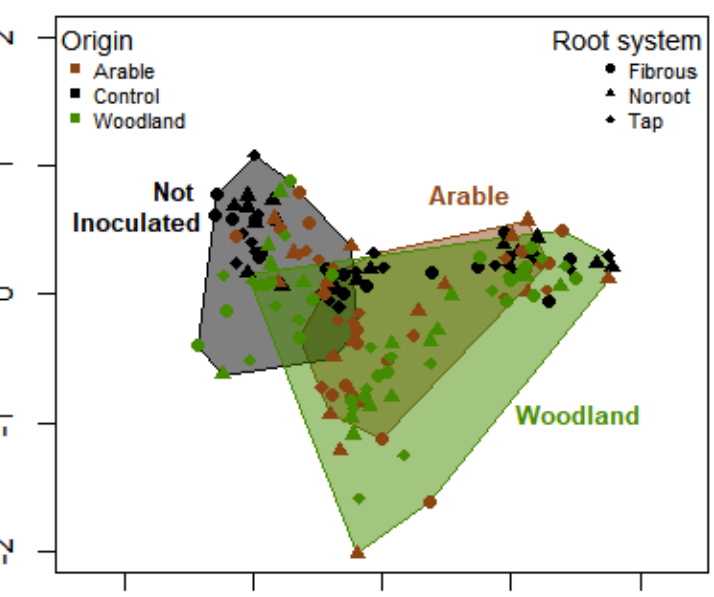

b)

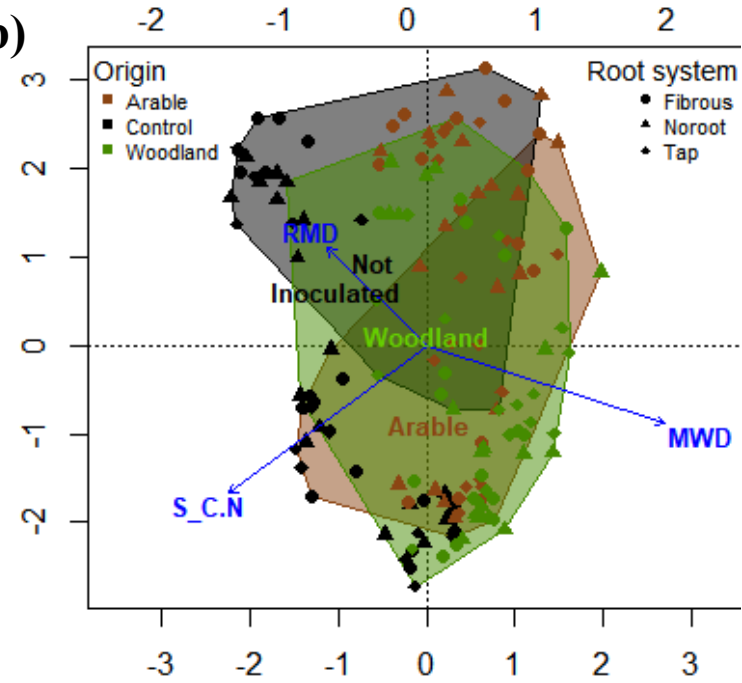

Fungi
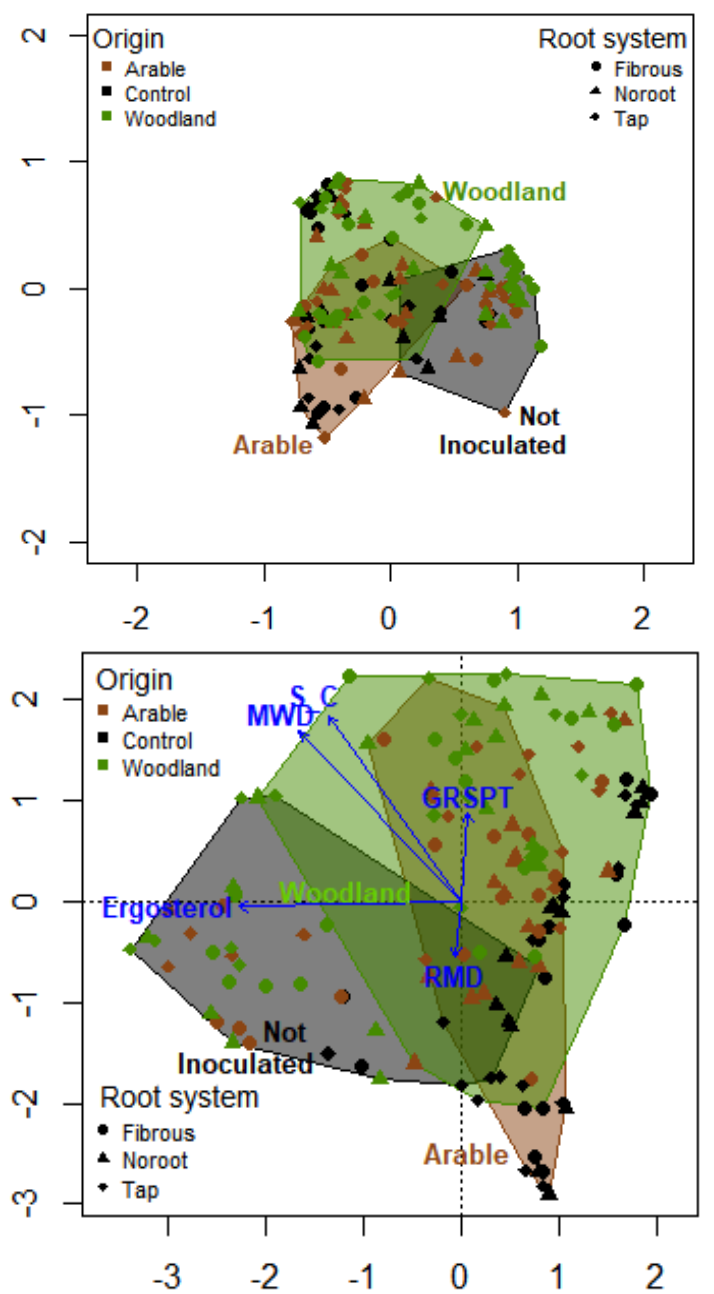

Figure 8. a) NMDS ordinations of bacteria and fungi species matrices with convex hull polygons containing plots of the three inoculation treatments (not inoculated, woodland and arable) and b)

graphs of dbRDA constrained ordinations of bacteria and fungi species matrices with convex hull polygons containing plots of the three inoculation treatments (not inoculated, woodland and arable) and significant variables obtained by automatic backward stepwise model building. Acronyms are:

S_C is soil total carbon, S_C.N is soil C:N ratio, MWD is mean weight diameter, RMD is root mean diameter, GRSPT is total glomalin related soil proteins. 
944 Adhikari, K., Hartemink, A.E., 2016. Linking soils to ecosystem services - A global review. Geoderma 945 262, 101-111.

946 Al-Ani, A.N., Dudas, M.J., 1988. Influence of calcium carbonate on mean weight diameter of soil. Soil

Ayuke, F.O., Brussaard, L., Vanlauwe, B., Six, J., Lelei, D.K., Kibunja, C.N., Pulleman, M.M., 2011. Soil fertility management: Impacts on soil macrofauna, soil aggregation and soil organic matter allocation. Applied Soil Ecology 48, 53-62.

Balesdent, J., Chenu, C., Balabane, M., 2000. Relationship of soil organic matter dynamics to physical protection and tillage. Soil and Tillage Research 53, 215-230.

Bardgett, R.D., Leemans, D.K., Cook, R., Hobbs, P.J., 1997. Seasonality of the soil biota of grazed and ungrazed hill grasslands. Soil Biology and Biochemistry 29, 1285-1294.

Barto, E.K., Alt, F., Oelmann, Y., Wilcke, W., Rillig, M.C., 2010. Contributions of biotic and abiotic factors to soil aggregation across a land use gradient. Soil Biology and Biochemistry 42, 2316-2324. Bast, A., Wilcke, W., Graf, F., Lüscher, P., Gärtner, H., 2016. Does mycorrhizal inoculation improve plant survival, aggregate stability, and fine root development on a coarse-grained soil in an alpine eco-engineering field experiment? Journal of Geophysical Research: Biogeosciences 121, 2158-2171. Baumert, V.L., Vasilyeva, N.A., Vladimirov, A.A., Meier, I.C., Kögel-Knabner, I., Mueller, C.W., 2018. Root Exudates Induce Soil Macroaggregation Facilitated by Fungi in Subsoil. Frontiers in Environmental Science 6.

Bearden, B., Petersen, L., 2000. Influence of arbuscular mycorrhizal fungi on soil structure and aggregate stability of a vertisol. Plant and Soil, 173-183.

Bergmann, G.T., Bates, S.T., Eilers, K.G., Lauber, C.L., Caporaso, J.G., Walters, W.A., Knight, R., Fierer, N., 2011. The under-recognized dominance of Verrucomicrobia in soil bacterial communities. Soil biology \& biochemistry 43, 1450-1455.

Bever, J.D., Platt, T.G., Morton, E.R., 2012. Microbial population and community dynamics on plant roots and their feedbacks on plant communities. Annual Review of Microbiology 66, 265-283. Bossuyt, H., Denef, K., Six, J., Frey, S.D., Merckx, R., Paustian, K., 2001. Influence of microbial populations and residue quality on aggregate stability. Applied Soil Ecology 16, 195-208. Brax, M., Buchmann, C., Kenngott, K., Schaumann, G.E., Diehl, D., 2020. Influence of the physicochemical properties of root mucilage and model substances on the microstructural stability of sand. Biogeochemistry 147, 35-52.

Brunel, C., Pouteau, R., Dawson, W., Pester, M., Ramirez, K.S., van Kleunen, M., 2020. Towards Unraveling Macroecological Patterns in Rhizosphere Microbiomes. Trends in Plant Science. Bulgarelli, D., Garrido-Oter, R., Münch, Philipp C., Weiman, A., Dröge, J., Pan, Y., McHardy, Alice C., Schulze-Lefert, P., 2015. Structure and Function of the Bacterial Root Microbiota in Wild and Domesticated Barley. Cell Host \& Microbe 17, 392-403.

Bulgarelli, D., Rott, M., Schlaeppi, K., Ver Loren van Themaat, E., Ahmadinejad, N., Assenza, F., Rauf, P., Huettel, B., Reinhardt, R., Schmelzer, E., Peplies, J., Gloeckner, F.O., Amann, R., Eickhorst, T., Schulze-Lefert, P., 2012. Revealing structure and assembly cues for Arabidopsis root-inhabiting bacterial microbiota. Nature 488, 91-95.

Butt, N., Campbell, G., Malhi, Y., Morecroft, M., Fenn, K., Thomas, M., 2009. Initial Results from Establishment of a Long-term Broadleaf Monitoring Plot at Wytham Woods, Oxford, UK. Carbonetto, B., Rascovan, N., Álvarez, R., Mentaberry, A., Vázquez, M.P., 2014. Structure, composition and metagenomic profile of soil microbiomes associated to agricultural land use and tillage systems in Argentine Pampas. PLOS ONE 9, e99949-e99949.

Carter, M., Kunelius, H., Angers, D., 1994. Soil Structural Form and Stability, and Organic Matter Under Cool-Season Perennial Grasses. Soil Science Society of America Journal - SSSAJ 58. Chenu, C., Le Bissonnais, Y., Arrouays, D., 2000. Organic Matter Influence on Clay Wettability and Soil Aggregate Stability. Soil Science Society of America Journal 64, 1479-1486. 
Chenu, C., Sotzky, G., 2002. Interactions Between Microorganisms and Soil Particles, Interactions between soil particles and microorganisms, pp. 3-40.

Chotte, J.-L., 2005. Importance of Microorganisms for Soil Aggregation, Microorganisms in Soils: Roles in Genesis and Functions, pp. 107-119.

Cissé, G., van Oort, F., Chenu, C., Essi, M., Staunton, S., 2020. Is the operationally defined fraction of soil organic matter, "GRSP" (glomalin-related soil protein), stable in soils? Evidence from trends in long-term bare fallow soil. European Journal of Soil Science 10.1111/ejss.12974. Commander, L.E., Merritt, D.J., Rokich, D.P., Dixon, K.W., 2009. Seed biology of Australian arid zone species: Germination of 18 species used for rehabilitation. Journal of Arid Environments 73, 617-625. Cui, J., Holden, N.M., 2015. The relationship between soil microbial activity and microbial biomass, soil structure and grassland management. Soil and Tillage Research 146, 32-38.

de Castro, A.P., Quirino, B.F., Pappas, G., Jr., Kurokawa, A.S., Neto, E.L., Kruger, R.H., 2008. Diversity of soil fungal communities of Cerrado and its closely surrounding agriculture fields. Archives of Microbiology 190, 129-139.

Degens, B.P., 1997. Macro-aggregation of soils by biological bonding and binding mechanisms and the factors affecting these: a review. Soil Research 35, 431-460.

Delelegn, Y.T., Purahong, W., Blazevic, A., Yitaferu, B., Wubet, T., Göransson, H., Godbold, D.L., 2017. Changes in land use alter soil quality and aggregate stability in the highlands of northern Ethiopia. Scientific Reports 7, 13602.

Denef, K., Six, J., 2005. Clay mineralogy determines the importance of biological versus abiotic processes for macroaggregate formation and stabilization. European Journal of Soil Science 56, 469479.

Dennis, P.G., Miller, A.J., Hirsch, P.R., 2010. Are root exudates more important than other sources of rhizodeposits in structuring rhizosphere bacterial communities? FEMS Microbiology Ecology 72, 313327.

DeSantis, T.Z., Hugenholtz, P., Larsen, N., Rojas, M., Brodie, E.L., Keller, K., Huber, T., Dalevi, D., Hu, P., Andersen, G.L., 2006. Greengenes, a Chimera-Checked 16S rRNA Gene Database and Workbench Compatible with ARB. Applied and Environmental Microbiology 72, 5069-5072.

Donn, S., Kirkegaard, J.A., Perera, G., Richardson, A.E., Watt, M., 2015. Evolution of bacterial communities in the wheat crop rhizosphere. Environmental Microbiology 17, 610-621.

Dray, S., Dufour, A.-B., 2007. The ade4 Package: Implementing the Duality Diagram for Ecologists. Journal of Statistical Software 22, 1-20.

Drenovsky, R.E., Steenwerth, K.L., Jackson, L.E., Scow, K.M., 2010. Land use and climatic factors structure regional patterns in soil microbial communities. Global Ecology and Biogeography 19, 2739.

Duchicela, J., Sullivan, T.S., Bontti, E., Bever, J.D., 2013. Soil aggregate stability increase is strongly related to fungal community succession along an abandoned agricultural field chronosequence in the Bolivian Altiplano. Journal of Applied Ecology.

Duchicela, J., Vogelsang, K.M., Schultz, P.a., Kaonongbua, W., Middleton, E.L., Bever, J.D., 2012. Nonnative plants and soil microbes: potential contributors to the consistent reduction in soil aggregate stability caused by the disturbance of North American grasslands. New Phytologist 196, 212-222. Eilers, K.G., Lauber, C.L., Knight, R., Fierer, N., 2010. Shifts in bacterial community structure associated with inputs of low molecular weight carbon compounds to soil. Soil Biology and Biochemistry 42, 896-903.

Fanin, N., Bertrand, I., 2016. Aboveground litter quality is a better predictor than belowground microbial communities when estimating carbon mineralization along a land-use gradient. Soil Biology and Biochemistry 94, 48-60.

Fierer, N., Bradford, M.A., Jackson, R.B., 2007. Toward an ecological classification of soil bacteria. Ecology 88, 1354-1364. 
Fierer, N., Lauber, C.L., Ramirez, K.S., Zaneveld, J., Bradford, M.A., Knight, R., 2012. Comparative metagenomic, phylogenetic and physiological analyses of soil microbial communities across nitrogen gradients. The ISME Journal 6, 1007-1017. Fitter, A.H., Peat, H.J., 1994. The Ecological Flora Database. Journal of Ecology 82, 415-425. Gispert, M., Emran, M., Pardini, G., Doni, S., Ceccanti, B., 2013a. The impact of land management and abandonment on soil enzymatic activity, glomalin content and aggregate stability. Geoderma 202-203, 51-61. and abandonment on soil enzymatic activity, glomalin content and aggregate stability. Geoderma 202-203, 51-61.

Goebel, M.-O., Woche, S.K., Bachmann, J., 2009. Do soil aggregates really protect encapsulated organic matter against microbial decomposition? Biologia 64, 443-448.

Graf, F., Frei, M., 2013. Soil aggregate stability related to soil density, root length, and mycorrhiza using site-specific Alnus incana and Melanogaster variegatus s.l. Ecological Engineering 57, 314-323. Gupta, V.V.S.R., Germida, J.J., 2015. Soil aggregation: Influence on microbial biomass and implications for biological processes. Soil Biology and Biochemistry 80, A3-A9.

Gweon, H.S., Oliver, A., Taylor, J., Booth, T., Gibbs, M., Read, D.S., Griffiths, R.I., Schonrogge, K., 2015. PIPITS: an automated pipeline for analyses of fungal internal transcribed spacer sequences from the Illumina sequencing platform. Methods in Ecology and Evolution 6, 973-980. Harris, R.F., Chesters, G., Allen, O.N., Attoe, O.J., 1964. Mechanisms Involved in Soil Aggregate Stabilization by Fungi and Bacteria. Soil Science Society of America Journal 28, 529-532. Hartmann, M., Howes, C.G., VanInsberghe, D., Yu, H., Bachar, D., Christen, R., Henrik Nilsson, R., Hallam, S.J., Mohn, W.W., 2012. Significant and persistent impact of timber harvesting on soil microbial communities in Northern coniferous forests. The ISME Journal 6, 2199-2218.

Helgason, B.L., Walley, F.L., Germida, J.J., 2010. No-till soil management increases microbial biomass and alters community profiles in soil aggregates. Applied Soil Ecology 46, 390-397.

Ho, A., Di Lonardo, D.P., Bodelier, P.L.E., 2017. Revisiting life strategy concepts in environmental microbial ecology. FEMS Microbiology Ecology 93.

Hudek, C., Stanchi, S., D'Amico, M., Freppaz, M., 2017. Quantifying the contribution of the root system of alpine vegetation in the soil aggregate stability of moraine. International Soil and Water Conservation Research 5, 36-42.

Hurisso, T.T., Moebius-Clune, D.J., Culman, S.W., Moebius-Clune, B.N., Thies, J.E., van Es, H.M., 2018. Soil Protein as a Rapid Soil Health Indicator of Potentially Available Organic Nitrogen. Agricultural \& Environmental Letters 3, 180006.

Huysman, F., Verstraete, W., 1993. Effect of cell surface characteristics on the adhesion of bacteria to soil particles. Biology and Fertility of Soils 16, 21-26.

Ihrmark, K., Bodeker, I.T., Cruz-Martinez, K., Friberg, H., Kubartova, A., Schenck, J., Strid, Y., Stenlid, J., Brandstrom-Durling, M., Clemmensen, K.E., Lindahl, B.D., 2012. New primers to amplify the fungal ITS2 region--evaluation by 454-sequencing of artificial and natural communities. FEMS Microbiology Ecology 82, 666-677.

Jie, C., Jing-zhang, C., Man-zhi, T., Zi-tong, G., 2002. Soil degradation: a global problem endangering sustainable development. Journal of Geographical Sciences 12, 243-252.

Jones, D.L., Nguyen, C., Finlay, R.D., 2009. Carbon flow in the rhizosphere: carbon trading at the soilroot interface. Plant and Soil 321, 5-33.

Koljalg, U., Nilsson, R.H., Abarenkov, K., Tedersoo, L., Taylor, A.F., Bahram, M., Bates, S.T., Bruns, T.D., Bengtsson-Palme, J., Callaghan, T.M., Douglas, B., Drenkhan, T., Eberhardt, U., Duenas, M., Grebenc, T., Griffith, G.W., Hartmann, M., Kirk, P.M., Kohout, P., Larsson, E., Lindahl, B.D., Lucking, R., Martin, M.P., Matheny, P.B., Nguyen, N.H., Niskanen, T., Oja, J., Peay, K.G., Peintner, U., Peterson, M., Poldmaa, K., Saag, L., Saar, I., Schussler, A., Scott, J.A., Senes, C., Smith, M.E., Suija, A., Taylor, D.L., Telleria, M.T., Weiss, M., Larsson, K.H., 2013. Towards a unified paradigm for sequence-based identification of fungi. Molecular Ecology 22, 5271-5277. 
Kozich, J.J., Westcott, S.L., Baxter, N.T., Highlander, S.K., Schloss, P.D., 2013. Development of a dualindex sequencing strategy and curation pipeline for analyzing amplicon sequence data on the MiSeq Illumina sequencing platform. Applied and Environmental Microbiology 79, 5112-5120.

Lauber, C.L., Hamady, M., Knight, R., Fierer, N., 2009. Pyrosequencing-Based Assessment of Soil pH as a Predictor of Soil Bacterial Community Structure at the Continental Scale. Applied and Environmental Microbiology 75, 5111-5120.

Lauber, C.L., Strickland, M.S., Bradford, M.A., Fierer, N., 2008. The influence of soil properties on the structure of bacterial and fungal communities across land-use types. Soil Biology and Biochemistry 40, 2407-2415.

Lavee, H., Sarah, P., Imeson, A.C., 1996. Aggregate Stability Dynamics as Affected by Soil Temperature and Moisture Regimes. Geografiska Annaler. Series A, Physical Geography 78, 73-82. Lavelle, P., Spain, A., Fonte, S., Bedano, J.C., Blanchart, E., Galindo, V., Grimaldi, M., Jimenez, J.J., Velasquez, E., Zangerlé, A., 2020. Soil aggregation, ecosystem engineers and the C cycle. Acta Oecologica 105, 103561.

Le Bissonnais, Y., 1996. Aggregate stability and assessment of soil crustability and erodibility: I. Theory and methodology. European Journal of Soil Science 47, 425-437. Lee, K., Foster, R., 1991. Soil fauna and soil structure. Soil Research 29, 745-775. Lehmann, A., Zheng, W., Rillig, M.C., 2017. Soil biota contributions to soil aggregation. Nat Ecol Evol 1, 1828-1835.

Lladó, S., Baldrian, P., 2017. Community-level physiological profiling analyses show potential to identify the copiotrophic bacteria present in soil environments. PLOS ONE 12, e0171638-e0171638. Lorenz, K., Lal, R., Preston, C.M., Nierop, K.G.J., 2007. Strengthening the soil organic carbon pool by increasing contributions from recalcitrant aliphatic bio(macro)molecules. Geoderma 142, 1-10. Mao, Y., Li, X., Smyth, E.M., Yannarell, A.C., Mackie, R.I., 2014. Enrichment of specific bacterial and eukaryotic microbes in the rhizosphere of switchgrass (Panicum virgatum L.) through root exudates. Environmental Microbiology Reports 6, 293-306.

Marín, C., Godoy, R., Valenzuela, E., Schloter, M., Wubet, T., Boy, J., Gschwendtner, S., 2017. Functional land-use change effects on soil fungal communities in Chilean temperate rainforests. Journal of Soil Science and Plant Nutrition 17, 985-1002.

Merino-Martín, L., Griffiths, R.I., Gweon, H.S., Furget-Bretagnon, C., Oliver, A., Mao, Z., Le Bissonnais, Y., Stokes, A., 2020. Rhizosphere bacteria are more strongly related to plant root traits than fungi in temperate montane forests: insights from closed and open forest patches along an elevational gradient. Plant and Soil.

Miller, R., Jastrow, J., 1992. The Role of Mycorrhizal Fungi in Soil Conservation, pp. 29-44. Miller, R.M., Jastrow, J.D., 1990. Hierarchy of root and mycorrhizal fungal interactions with soil aggregation. Soil Biology and Biochemistry 22, 579-584.

Morel, J.L., Habib, L., Plantureux, S., Guckert, A., 1991. Influence of maize root mucilage on soil aggregate stability. Plant and Soil 136, 111-119.

Mueller, R.C., Rodrigues, J.L.M., Nüsslein, K., Bohannan, B.J.M., 2016. Land use change in the Amazon rain forest favours generalist fungi. Functional Ecology 30, 1845-1853.

Oades, J., Waters, A., 1991. Aggregate hierarchy in soils. Soil Research 29, 815-828.

Oksanen, J., Blanchet, F.G., Friendly, M., Kindt, R., Legendre, P., McGlinn, D., Minchin, P.R., O'Hara, R.B., Simpson, G.L., Solymos, P., Stevens, M.H.H., Szoecs, E., Wagner, H., 2019. vegan: Community Ecology Package, R package version 2.5-6. https://CRAN.R-project.org/package=vegan.

Or, D., Smets, B.F., Wraith, J.M., Dechesne, A., Friedman, S.P., 2007. Physical constraints affecting bacterial habitats and activity in unsaturated porous media - a review. Advances in Water Resources 30, 1505-1527.

Orgiazzi, A., Lumini, E., Nilsson, R.H., Girlanda, M., Vizzini, A., Bonfante, P., Bianciotto, V., 2012. Unravelling Soil Fungal Communities from Different Mediterranean Land-Use Backgrounds. PLOS ONE 7, e34847. 

and heritability of the maize rhizosphere microbiome under field conditions. Proceedings of the National Academy of Sciences 110, 6548-6553. Peng, X., Horn, R., Hallett, P., 2015. Soil structure and its functions in ecosystems: Phase matter \& scale matter. Soil and Tillage Research 146, 1-3. Philippot, L., Raaijmakers, J.M., Lemanceau, P., van der Putten, W.H., 2013. Going back to the roots: the microbial ecology of the rhizosphere. Nature Reviews. Microbiology 11, 789-799. Plassard, C., Bonafos, B., Touraine, B., 2000. Differential effects of mineral and organic N sources, and of ectomycorrhizal infection by Hebeloma cylindrosporum, on growth and $\mathrm{N}$ utilization in Pinus pinaster. Plant, Cell \& Environment 23, 1195-1205.

Poirier, V., Roumet, C., Angers, D.A., Munson, A.D., 2018. Species and root traits impact macroaggregation in the rhizospheric soil of a Mediterranean common garden experiment. Plant and Soil 424, 289-302.

R Core Team, 2019. R: A Language and Environment for Statistical Computing. R Foundation for Statistical Computing, Vienna, Austria. URL https://www.R-project.org/.

Rillig, M.C., Lehmann, A., Aguilar-Trigueros, C.A., Antonovics, J., Caruso, T., Hempel, S., Lehmann, J., Valyi, K., Verbruggen, E., Veresoglou, S.D., Powell, J.R., 2016. Soil microbes and community coalescence. Pedobiologia 59, 37-40.

Rillig, M.C., Muller, L.A.H., Lehmann, A., 2017. Soil aggregates as massively concurrent evolutionary incubators. ISME J 11, 1943-1948.

1163 Rillig, M.C., Mummey, D.L., 2006. Mycorrhizas and soil structure. New Phytologist 171, 41-53.

1164 Rillig, M.C., Wright, S.F., Eviner, V.T., 2002a. The role of arbuscular mycorrhizal fungi and glomalin in soil aggregation: comparing effects of five plant species. Plant and Soil 238, 325-333. Rillig, M.C., Wright, S.F., Shaw, M.R., Field, C.B., 2002b. Artificial climate warming positively affects arbuscular mycorrhizae but decreases soil aggregate water stability in an annual grassland. Oikos 97, 52-58.

Rognes, T., Flouri, T., Nichols, B., Quince, C., Mahé, F., 2016. VSEARCH: a versatile open source tool for metagenomics. PeerJ 4, e2584. Rutherford, P.M., Juma, N.G., 1992. Influence of texture on habitable pore space and bacterialprotozoan populations in soil. Biology and Fertility of Soils 12, 221-227. typic ustochrepts of Northwest India. Plant and Soil 339, 457-470.

Saleem, M., Law, A.D., Sahib, M.R., Pervaiz, Z.H., Zhang, Q., 2018. Impact of root system architecture on rhizosphere and root microbiome. Rhizosphere 6, 47-51.

Sarathchandra, S.U., Perrott, K.W., Boase, M.R., Waller, J.E., 1988. Seasonal changes and the effects of fertiliser on some chemical, biochemical and microbiological characteristics of high-producing pastoral soil. Biology and Fertility of Soils 6, 328-335.

Savill, P.S.S., Perrins, C., Kirby, K., Fisher, N., 2011. Wytham Woods: Oxford's Ecological Laboratory. Wytham Woods: Oxford's Ecological Laboratory, 1-288.

Shi, S., Nuccio, E., Herman, D.J., Rijkers, R., Estera, K., Li, J., da Rocha, U.N., He, Z., Pett-Ridge, J., Brodie, E.L., Zhou, J., Firestone, M., 2015. Successional Trajectories of Rhizosphere Bacterial Communities over Consecutive Seasons. mBio 6, e00746-00715.

Six, J., Bossuyt, H., Degryze, S., Denef, K., 2004. A history of research on the link between (micro)aggregates, soil biota, and soil organic matter dynamics. Soil and Tillage Research 79, 7-31. Six, J., Elliott, E.T., Paustian, K., Doran, J.W., 1998. Aggregation and Soil Organic Matter Accumulation in Cultivated and Native Grassland Soils. Soil Science Society of America Journal 62, 1367-1377. Steenwerth, K.L., Jackson, L.E., Calderón, F.J., Stromberg, M.R., Scow, K.M., 2002. Soil microbial community composition and land use history in cultivated and grassland ecosystems of coastal California. Soil Biology and Biochemistry 34, 1599-1611.

Thomson, B.C., Tisserant, E., Plassart, P., Uroz, S., Griffiths, R.I., Hannula, S.E., Buée, M., Mougel, C., Ranjard, L., Van Veen, J.A., Martin, F., Bailey, M.J., Lemanceau, P., 2015. Soil conditions and land use 
intensification effects on soil microbial communities across a range of European field sites. Soil Biology and Biochemistry 88, 403-413.

Tindall, B.J., Rossello-Mora, R., Busse, H.J., Ludwig, W., Kampfer, P., 2010. Notes on the characterization of prokaryote strains for taxonomic purposes. Int J Syst Evol Microbiol 60, 249-266. Tisdall, J.M., 1994. Possible role of soil microorganisms in aggregation in soils. Plant and Soil 159, 115-121.

Trivedi, P., Delgado-Baquerizo, M., Jeffries, T.C., Trivedi, C., Anderson, I.C., Lai, K., McNee, M., Flower, K., Pal Singh, B., Minkey, D., Singh, B.K., 2017. Soil aggregation and associated microbial communities modify the impact of agricultural management on carbon content. Environmental Microbiology 19, 3070-3086. USS Working Group WRB, 2014. World Reference Base for soil resources 2014: international soil classification system for naming soils and creating legends for soil maps. World Soil Resources Reports No. 106. FAO, Rome. van de Voorde, T.F.J., van der Putten, W.H., Bezemer, T.M., 2012. Soil inoculation method determines the strength of plant-soil interactions. Soil Biology and Biochemistry 55, 1-6. van der Putten, W.H., Bardgett, R.D., Bever, J.D., Bezemer, T.M., Casper, B.B., Fukami, T., Kardol, P., Klironomos, J.N., Kulmatiski, A., Schweitzer, J.A., Suding, K.N., Van de Voorde, T.F.J., Wardle, D.A., 2013. Plant-soil feedbacks: the past, the present and future challenges. Journal of Ecology 101, 265276.

Van Soest, P.J., 1963. Use of detergents in the analysis of fibrous feeds. 2. A rapid method for the determination of fiber and lignin. Journal of the Association of Official Agricultural Chemists 46, 829835.

van Veen, J.A., van Overbeek, L.S., van Elsas, J.D., 1997. Fate and activity of microorganisms introduced into soil. Microbiology and Molecular Biology Reviews 61, 121-135.

Wang, Q., Garrity, G.M., Tiedje, J.M., Cole, J.R., 2007. Naïve Bayesian Classifier for Rapid Assignment of rRNA Sequences into the New Bacterial Taxonomy. Applied and Environmental Microbiology 73, 5261-5267.

Wright, S.F., Upadhyaya, A., 1996. Extraction of an abundant and unusual protein from soil and comparison with hyphal protein of arbuscular mycorrhizal fungi. Soil Science 161, 575-586. Wu, X., Wei, Y., Wang, J., Wang, D., She, L., Wang, J., Cai, C., 2017. Effects of soil physicochemical properties on aggregate stability along a weathering gradient. CATENA 156, 205-215.

Zhang, J., Kobert, K., Flouri, T., Stamatakis, A., 2014. PEAR: a fast and accurate Illumina Paired-End reAd mergeR. Bioinformatics 30, 614-620.

Zhang, S., Li, Q., Lü, Y., Zhang, X., Liang, W., 2013. Contributions of soil biota to C sequestration varied with aggregate fractions under different tillage systems. Soil Biology and Biochemistry 62, 147-156.

Zhang, S., Li, Q., Zhang, X., Wei, K., Chen, L., Liang, W., 2012. Effects of conservation tillage on soil aggregation and aggregate binding agents in black soil of Northeast China. Soil and Tillage Research $124,196-202$. 

Supplementary Material for online publication only
Click here to download Supplementary Material for Click here to download Supplementary Material for online publication only: Supplementary material.docx . 


\section{Declaration of interests}

$\bigotimes$ The authors declare that they have no known competing financial interests or personal relationships that could have appeared to influence the work reported in this paper.

$\square$ The authors declare the following financial interests/personal relationships which may be considered as potential competing interests:

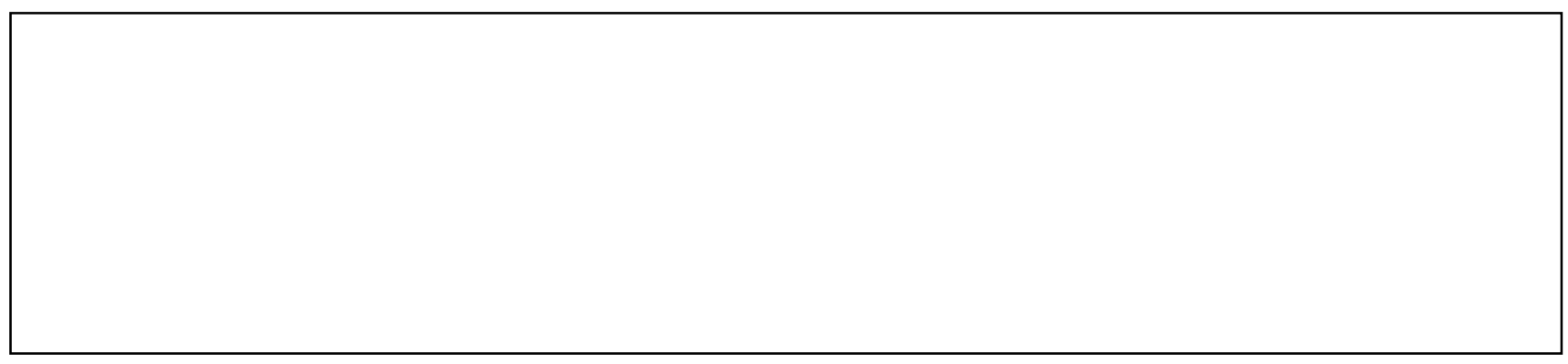

